\title{
1 Organo-mineral associations largely contribute to 2 the stabilization of century-old pyrogenic organic 3 matter in cropland soils.
}

4 Victor Burgeon ${ }^{a}$, Julien Fouchéa,b, Jens Leifeld ${ }^{c}$, Claire Chenu ${ }^{d}$, Jean-Thomas Cornélis ${ }^{a}$

5 a TERRA, Teaching and Research Centre, Gembloux Agro-Bio Tech, University of Liège, Gembloux 5030,

6 Belgium

7 b LISAH, Univ Montpellier, INRAE, IRD, Institut Agro, Montpellier, France

$8{ }^{c}$ Climate and Agriculture Group, Agroscope, Reckenholzstrasse 191, 8046 Zurich, Switzerland

$9 \quad$ d UMR Ecosys, Université Paris-Saclay, INRAE, AgroParisTech, 78850 Thiverval-Grignon, France

10 Burgeon, victor.burgeon@uliege.be

11 Fouché, julien.fouche@supagro.fr

12 Leifeld, jens.leifeld@agroscope.admin.ch

13 Chenu, claire.chenu@inra.fr

14 Cornelis, jtcornelis@uliege.be 
Understanding the processes underlying carbon (C) stability in soils is of utmost importance in the context of climate change. In this setting, biochar is often studied for its persistence in soils and reported to have positive impacts on soil fertility. Whilst recent research has mostly focused on the short-term effects of biochar amendments to soil, a better understanding of its long-term persistence in soils is needed.

Our study focuses on agricultural soils enriched in charcoal residues, produced in preindustrial kiln sites ca. 220 years ago, as a proxy for aged biochar. Our aim is to better understand the processes governing the long-term persistence of pyrogenic organic matter (PyOM) in cultivated soils. To achieve this, we focus on i) the effect of PyOM on soil aggregation, ii) its distribution amongst soil fractions and iii) its chemical and thermal properties. For this purpose, we combined a soil particle size-density fractionation with elemental and thermal analyses on topsoil samples collected in charcoal enriched (CHAR) and adjacent reference (REF) soils in a conventionally cropped field in Wallonia (Belgium).

The presence of charcoal in soils resulted in a $91 \pm 34 \%$ higher C content in CHAR soils than REF soils, of which 84 to $94 \%$ was PyOM and 6 to $16 \%$ was additional non-PyOM. In CHAR soils, macroaggregation was promoted at the expense of microaggregation (CHAR MACRO $=48.9 \pm 12.8 ;$ CHAR $_{\text {MICRO }}=25.5 \pm 8.3 \mathrm{~g}$

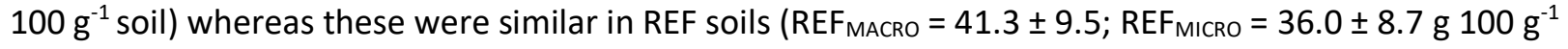
soil). Elemental and thermal analyses revealed that PyOM did not only occur as free light fractions but was also occluded in aggregates or sorbed onto mineral phases (56.4 $\pm 22.9 \%$ of total PyOM) suggesting PyOM may be further stabilized through organo-mineral associations. Century-old PyOM showed increased $\mathrm{H}: \mathrm{C}$ and $\mathrm{O}: \mathrm{C}$ atomic ratios compared to recently pyrolyzed $\mathrm{OM}$, particularly in occluded as opposed to free light fractions, vouching for the functionalization of its surfaces. Furthermore, regardless of high C contents in CHAR soils, similar C:N ratios between studied soils in mineral dominated fractions suggested increased amounts of $\mathrm{N}$-rich non-PyOM in charcoal rich soils. Our results demonstrate that, over centuries in cultivated soils, PyOM plays an active role in aggregation patterns. We conclude that century old PyOM is broken down from coarse to fine particles, and through functionalization of its surface contributes to organo-mineral associations. Beyond its intrinsic chemical recalcitrance, the long-term persistence of biochar is enhanced by occlusion and sorption processes.

\section{Keywords:}




\section{Introduction}

Globally, human land use and agriculture in particular have resulted in a substantial loss of soil organic $C$ (SOC) (Sanderman et al., 2017). As soil organic matter (OM) plays a crucial role in both the global C cycle and in ensuring food security (Le Quéré et al., 2009; Chenu et al., 2019) implementing practices that allow for SOC restoration and sequestration in cultivated soils offers a great potential to contribute to the mitigation of anthropogenic greenhouse gas emissions, whilst improving soil agronomic and ecological functions (Lal, 2004; Minasny et al., 2017; Chenu et al., 2019).

Amongst the various strategies allowing for $\mathrm{SOC}$ sequestration (i.e., a net removal of atmospheric $\mathrm{CO}_{2}$ ), the study of $\mathrm{C}$ forms displaying long residence times in soils such as biochar has received much attention. Biochar is a form of pyrogenic organic matter (PyOM) whose purpose is to be amended to soils for its conjoint potential in terms of long-term C storage (centennial or longer)(Forbes et al., 2006) as well as soil fertility improvement (Lehmann et al., 2006). Meta-analyses of short-term (annual to decadal) biochar impacts in agro-ecosystems report an overall increased plant productivity as explained by the increase in soil water holding capacity, plant nutrient availability and liming effects (Jeffery et al., 2011; Biederman and Harpole, 2013). Such changes are particularly marked in highly weathered, coarse textured, tropical soils (Crane-Droesch et al., 2013). Biochar properties and their resulting agronomic benefits depend on its organic precursor and the pyrolysis conditions (e.g., heating rates and maximum temperatures) (Zimmerman et al., 2011; B. P. Singh et al., 2012; Baveye, 2014; Fang et al., 2015). Beyond reported positive impacts on soil fertility, biochar is studied for its potential as a $\mathrm{C}$ sequestration tool and related implications on the global $\mathrm{C}$ balance (Schmidt and Noack, 2000). The stability of biochar and PyOM in general is attributed to its aromatic moieties which confer it recalcitrance against biotic or abiotic oxidation (Hammes et al., 2008; Kuzyakov et al., 2014). The distribution and organization of these aromatic moieties in charcoal fragments are characterized by the aromaticity and degree of aromatic condensation of biochar (Wiedemeier et al., 2015) which will in turn determine its persistence in ecosystems (Hammes et al., 2008; Kuzyakov et al., 2014). Despite this persistence in soils, biochar properties evolve in soils over time through breakdown and functionalization (i.e., ageing) (Cheng et al., 2006; Nguyen et al., 2008; Cheng and Lehmann, 2009; Hardy et al., 2017b). Recent studies have shown that PyOM may decompose faster than initially predicted (Hamer et al., 2004; Hammes et al., 2008) and that the persistence of PyOM in soils may have been overestimated particularly in arable settings (Singh et al., 2012; Lehndorff et al., 2014; Lutfalla et al., 2017). The persistence of PyOM, as for other OM forms, in soils is therefore strongly dependant on ecosystem properties rather than solely inherited chemical recalcitrance (Schmidt et al., 2011; Lehmann and Kleber, 2015; Lehmann et al., 2020). Therefore, spatial inaccessibility for decomposer organisms (i.e., occlusion in aggregates) and interactions with mineral surfaces (i.e., adsorption) or metals (von Lützow et al., 2006; Kögel-Knabner et al., 2008) need to be carefully investigated as stabilization processes for PyOM in soils particularly as ageing renders it an active soil constituent.

While short-term biochar-induced changes in agro-ecosystems have been extensively characterized (Jeffery et al., 2011; Biederman and Harpole, 2013; Crane-Droesch et al., 2013), insights into its longterm effects are needed to verify its potential in climate-smart agriculture (Baveye, 2020). Worldwide various field models have been addressed to better understand the long-term fate of biochar in soils. 
Amongst these are the fertile Amazonian Dark Earth (Glaser and Birk, 2012), soils containing wildfire derived PyOM (Schmidt and Noack, 2000; Bird et al., 2015), historical industrial sites (Cheng et al., 2008b), crop residues burning or relic charcoal hearths sites (Borchard et al., 2014; Lehndorff et al., 2014; Hernandez-Soriano et al., 2016b; Kerré et al., 2016; Hardy et al., 2017a; Hirsch et al., 2017; Schneider et al., 2019). All these studies address aged PyOM however varying production environments may result in a final product differing from that obtained through oxygen regulated pyrolysis as is done today to produce biochar (Bird et al., 2015).

In southern Belgium, pre-industrial charcoal production kiln sites are easily spotted in agricultural fields as "black patches" (Hardy and Dufey, 2015). The charcoal still found in these sites stands as left-overs from the production kiln that has been incorporated in agro-ecosystems since their conversion from woodlands circa 150-200 years ago (Hardy et al., 2017a). Due to similar oxygen-limited conditions in kilns as those obtained in modern biochar production units, this setting is ideal for the study of centuryold biochar in temperate conventional cropping systems (Hardy et al., 2017a). Recent studies investigating similar kiln sites in the region showed that black patches stored 60 to $80 \%$ more $\mathrm{C}$ than adjacent reference soils in cropped systems, of which from $25 \%$ to $40 \%$ was non-pyrogenic organic matter (non-PyOM)(Hernandez-Soriano et al., 2016a; Kerré et al., 2016; Hardy et al., 2017a). The total N content as well as the $\mathrm{C}: \mathrm{N}$ and $\mathrm{C}: \mathrm{P}$ ratios are higher in kiln soils than reference soils (Hardy et al., 2017a). In addition, kiln soils display greater cation exchange capacity (CEC), which was associated with larger content of exchangeable $\mathrm{Ca}^{2+}$ and $\mathrm{Mg}^{2+}$ (Hardy et al., 2017a). Long-term ageing and continuous cultivation have resulted in the increase in $\mathrm{H}: \mathrm{C}$ and $\mathrm{O}: \mathrm{C}$ ratios of charcoal particles in comparison to freshly pyrolyzed OM (Hardy et al., 2017b). These modifications are associated with the oxidation of charcoal particles and the creation of functional groups (mostly carboxyl, phenol or carbonyl) at the edge of aromatic rings (Lehmann et al., 2005; Cheng et al., 2008a) which in turn promotes the precipitation of 2:1 phyllosilicates and $\mathrm{CaCO}_{3}$ on the surfaces of PyOM (Hardy et al., 2017b).

109

110

111

112

113

114

115

116

117

118

119

120

121

122

123

124

125
In the present study we aim to investigate the various associations between century-old biochar and soil minerals in order to assess their contribution to PyOM persistence in soils. For this purpose, we aim to separate SOC into pools displaying similar stabilization mechanisms (i.e., chemical recalcitrance, spatial inaccessibility, interactions with mineral surfaces)(von Lützow et al., 2006, 2007). Numerous physical (size, density) and chemical (oxidation, extraction) fractionation protocols have been developed to isolate SOC pools of comparable stabilization mechanisms and turnover rates (von Lützow et al., 2007; Poeplau et al., 2018). In soils, the most labile SOC pool, displaying turnover rates $<10$ years, are represented by free microbial biomass and the coarse light fraction (LF - density $<1.6-2 \mathrm{~g} \mathrm{~cm}^{-3}$ ) whereas the SOC pools with the highest turnover rates comprise the oxidation-resistant SOC pool and the heavy fraction after macroaggregate dispersion (HF - density $>2.8 \mathrm{~g} \mathrm{~cm}^{-3}$ )(von Lützow et al., 2007; Virto et al., 2010; Poeplau et al., 2018). In cultivated soils macroaggregates display rapid turnover as revealed by their composition of a mix of young and older SOC originating from both labile organic matter, (i.e., plant roots, mucilage, exudates, fungal hyphae, microbial biomass)(Rillig, 2004; Rasse et al., 2005) and more persistent physically protected and adsorbed organic compounds (Moni et al., 2010; Poeplau et al., 2018). Their dispersion is therefore required to isolate SOC groups with similar turnover rates (Virto et al., 2010; Poeplau et al., 2018). The few fractionation studies performed on soils enriched in aged biochar showed that the century-old biochar particles were mostly present as free particulate organic 
matter (i.e., non-associated with mineral particles)(Glaser et al., 2000; Herath et al., 2014; Kerré et al., 2016; Grunwald et al., 2017). However PyOM has also been reported to increase aggregate formation (Awad et al., 2013) and stability (Pituello et al., 2018) as well as to increase the abundance of non-PyOM in the aggregate-protected silt and clay fraction (Liang et al., 2010; Hernandez-Soriano et al., 2016a; Kerré et al., 2017) thus showing interactions with mineral phases.

Although the effects of PyOM in soils have been widely addressed, there is a lack of consensus concerning the processes involved in its long-term persistence. Nonetheless it is known that ageing in soils causes an oxidation of the charcoals surfaces and results in the formation of phenolic and carboxylic functional groups along with a charging of the structures surface (Cheng et al., 2008a; Nguyen et al., 2008; Cheng and Lehmann, 2009). As a result, physical protection through aggregation (Brodowski et al., 2006) as well as an increased association with the mineral phases (Nguyen et al., 2008; Rodionov et al., 2010; Hardy et al., 2017b) could play an important role in PyOM stabilization (Lehmann and Kleber, 2015) beyond its chemical recalcitrance to oxidation.

In this study, we investigated the long-term persistence of PyOM in soils. To achieve this, soil samples from five preindustrial charcoal kiln sites were compared to five adjacent reference soils in a conventionally farmed Luvisol (Isnes, Belgium). These charcoal kilns are visible as black spots on bare soils and procure an ideal setting for the study of aged biochar in conventionally cropped systems. This site hence serves as a proxy to study the long-term effect of biochar in soils if it was to become a common soil amendment in temperate soils of the region.

Our aim is to understand how and where PyOM persists in the soil matrix, as either free standing particulate OM (POM) or protected through aggregate occlusion or mineral sorption. In particular, this study aimed i) to quantify the effects of long-term PyOM accumulation on soil aggregation through a size and density fractionation protocol, ii) to investigate the distribution of PyOM amongst the fractions and iii) to determine the physico-chemical and thermal characteristics of organic matter in soil fractions. Numerous analytical techniques exist to identify, characterize and quantify PyOM; physical density separations, chemical oxidation, thermal analyses, optical or molecular marking techniques (Schmidt and Noack, 2000; Brodowski et al., 2005; Hammes et al., 2007; Leifeld, 2007; Plante et al., 2009; Bird et al., 2015; Kerré et al., 2016). Among these, thermal analyses and differential scanning calorimetry (DSC) in particular, has been reported to be an efficient way to quantify and characterize number of samples rapidly within the whole OM continuum, and was hence used to characterize PyOM forms (Leifeld, 2007; Plante et al., 2009).

We postulate that charcoal is found in all, light and heavy, soil fractions as a consequence of particle physical breakdown and functionalization of its surfaces. Furthermore, we postulate that the elemental composition of OM controls its thermal stability within the different fractions. Finally, we postulate that pyrogenic $\mathrm{C}$ forms may be further stabilized as a result of organo-mineral associations which increases its potential as a $\mathrm{C}$ sequestration tool. 


\section{Materials and Methods}

\subsection{Study site}

In cropped agroecosystems of the province of Namur (Belgium), century-old charcoal kiln sites are easily spotted visually in the field or by aerial imagery as darker ellipses on the soil surface (Figure 1). The site selected for this study is located in Isnes $\left(50^{\circ} 31^{\prime} \mathrm{N} 4^{\circ} 44^{\prime} \mathrm{E}\right)$ and was converted from forest to cropland at least 170 years ago as revealed by land occupation maps of Vandermaelen (1846-1854). Charcoal was produced in kiln sites during the pre-industrial era to meet energy demands thus providing an estimated age for the charcoal of interest of ca. 250 years (Hardy et al., 2017a). Hardy et al. (2017b) thoroughly characterized kiln sites of the region and reported that charcoal mixtures are generally dominated by deciduous hardwood such as oak (Quercus sp.), hornbeam (C. betulus), beech (F. sylvatica), hazel (Corylus avellana L.) and birch (Betula sp.).

The soil of the studied site has a homogeneous silt loam texture throughout and is slightly sloped (Table 1). It is characterized as a Haplic Luvisol (WRB, 2014) developed from decarbonated quaternary loess. The average annual precipitation is of $840 \mathrm{~mm}$ of rain and the mean annual temperature is $9.8^{\circ} \mathrm{C}$. The field follows a four-year crop rotation established approximately in 1985 and alternates between chicory, winter wheat, beet root, potatoes and cover crops (mustard and phacelia).

\section{\# Figure 1: Aerial view of the study site.}

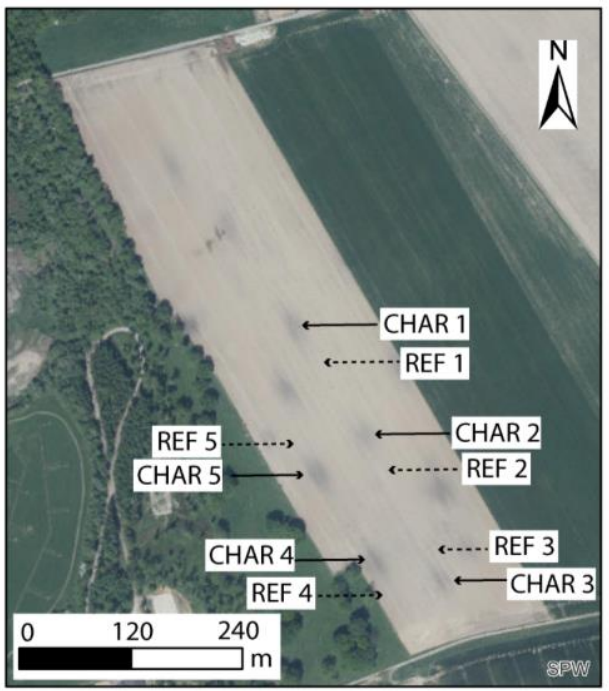

Figure 1 - Aerial view of the study site. Kiln sites are visible as black patches when the soil is bare. The image comes from the "Service Public de Wallonie: Orthophotos 2009/2010", arrows indicate the approximate location of the five soil sampling sites per studied soil.

\subsection{Soil sampling and characterization}

In this study, five field replicates of two soils, charcoal enriched (CHAR) and reference soils (REF) at least $40 \mathrm{~m}$ away from one another, were compared to study the effect of charcoal. Every soil sample collected for each of the five replicates of CHAR and REF sites was bulked from five cores sampled in the topsoil layer $(0-30 \mathrm{~cm})$ within a radius of $1 \mathrm{~m}$. These samples were dried at $40^{\circ} \mathrm{C}$ for $48 \mathrm{~h}$ before further analysis. 
A subsample of each soil was ground and sieved to $2 \mathrm{~mm}$ for baseline physico-chemical characterization. Briefly, $\mathrm{pH}$ was determined in distilled water and $\mathrm{KCl}(1 \mathrm{~N})$ (ratio soil: solution 1:5, ISO 10390). The soil particle-size distribution was determined by gravity sedimentation (NF X 31-107), C and N content were quantified by near infra-red spectrometry after flash dry combustion (respectively ISO 10694; ISO 13878). We measured the cation exchange capacity (CEC) by percolation of $1 \mathrm{M}$ ammonium acetate ( $\mathrm{pH}$ 7) on soil columns according to the Metson procedure (Metson, 1956). The bioavailable major elements, $\mathrm{Ca}, \mathrm{Mg}, \mathrm{P}$ and $\mathrm{K}$ were extracted using ammonium acetate-EDTA $1 \mathrm{M}(\mathrm{pH}=4.65$; (Lakanen and Erviö, 1971)) and quantified by atomic absorption spectroscopy (Ca, Mg, K) or spectrophotometry (P).

\subsection{Fractionation protocol}

Soil samples from both studied soils followed a four step fractionation protocol (Figure 2), which was adapted from the method described by Chenu and Plante, (2006), Gulde et al. (2008) and Virto et al. (2010). In the first step, wet sieving fractionated the soil into four fractions according to size ( $>2000 \mu \mathrm{m}$, coarse sand size: $2000-250 \mu \mathrm{m}$, fine sand size: $250-50 \mu \mathrm{m}$, silt and clay size $(S \& C)<50 \mu \mathrm{m})$. The particulate material bigger than $2 \mathrm{~mm}$ was discarded. The second step used density to differentiate light fractions (free $L F, d<1.85 \mathrm{~g} \mathrm{~cm}^{-3}$ ) from heavy fractions (HF: $d>1.85 \mathrm{~g} \mathrm{~cm}^{-3}$ ): Macroaggregate, microaggregate, free silt and clay size heavy fractions (free S\&C HF). Step 3 focused on breaking down the macroaggregates $(2000-250 \mu \mathrm{m})$ to isolate its components into three finer size class fractions (coarse sand, macroaggregate protected fine sand, macroaggregate protected-S\&C). Finally, step 4, through a sequential size and density fractionation and dispersion of microaggregates, isolated nonoccluded and occluded S\&C LF from S\&C-size HF within each size class sizes from step 1.

We used the wording free for LF and HF after wet sieving, and occluded for LF obtained after ultrasonic dispersion of aggregates. This fractionation protocol was applied on both studied soils, CHAR or REF, and for all five replicates.

\section{i. $\quad$ Step 1 - Size separation by wet sieving}

We applied the wet sieving size separation protocol presented by Six et al. (1998). A soil sample of $80 \mathrm{~g}$, previously air-dried at $40^{\circ} \mathrm{C}$ for $48 \mathrm{~h}$ was submerged in deionized water for $5 \mathrm{~min}$ prior to deposition in a water bath on a $2 \mathrm{~mm}$ sieve. The sieve was then moved up and down and tilted in a rotational movement for 50 rotations in two minutes at room temperature. The sieve was then removed from the water bath and its inner and outer walls were rinsed with deionized water. The reject ( $>2 \mathrm{~mm}$ ) was collected by back-washing in a glass tray and air dried at $60^{\circ} \mathrm{C}$. This wet sieving operation was repeated firstly using a $250 \mu \mathrm{m}$ sieve on the soil that went through the $2 \mathrm{~mm}$ sieve, then repeated a second time on a $50 \mu \mathrm{m}$ sieve to separate the two smallest fractions. All sieve rejects were back-washed in glass trays after rinsing the sieve and dried at $60^{\circ} \mathrm{C}$. This way four fractions per sample were differentiated as follows: particulate $(>2000 \mu \mathrm{m})>$ coarse sand size $(2000-250 \mu \mathrm{m})>$ fine sand size $(250-50 \mu \mathrm{m})>$ Silt \& Clay size materials $(<50 \mu \mathrm{m})$ (Figure 2-step1). 




Figure 2 - Flow-chart of the four step fractionation protocol. S\&C silt and clay; LF light fraction; HF heavy fraction; Mp macroaggregate protected; mp microaggregate protected; occ. occluded; non-occ non-occluded. Dashed squares highlight the difference between the three size classes

\section{ii. Step 2 - Density fractionation}

In this step we divided a $10 \mathrm{~g}$ subsample of the three size fractions smaller than $2 \mathrm{~mm}$ (coarse sand size $>$ fine sand size $>$ S\&C-size materials ) obtained from step 1 into a light fraction (LF) and a heavy fraction (HF) as described by Six et al. (1998). For this density separation subsamples were submerged in $30 \mathrm{~mL}$ of sodium polytungstate ( $\mathrm{SPT}, \mathrm{Na}_{6}\left(\mathrm{H}_{2} \mathrm{~W}_{12} \mathrm{O}_{40},-1.85 \mathrm{~g} \mathrm{~cm}^{-3}\right)$ in centrifuge tubes. These were then closed and gently stroked 10 times to remove bubbles and without breaking aggregates. The centrifuge tubes were then reopened and with an extra $20 \mathrm{ml}$ of SPT its inner walls were rinsed to gather all the sample in the solution. The samples were placed in a vacuum (-140 kPa) for $10 \mathrm{~min}$, left to rest for $20 \mathrm{~min}$ and centrifuged at $4700 \mathrm{~g}$ for $10 \mathrm{~min}$. The supernatant was transferred on a filtering flask where a gentle vacuum was applied (glass fiber filter Mechery-Nagel Germany, $\Phi=0.45 \mu \mathrm{m}$ ). After having repeated the centrifuge and the filtering thrice, the LF on the filter was thoroughly rinsed to remove the remaining SPT under a light vacuum. The LF was then recovered in a glass tray by gently back washing the filter with deionized water and then oven dried $\left(60^{\circ} \mathrm{C}\right)$.

To recover the HF, $50 \mathrm{ml}$ of deionized water was added to the pellet in a centrifuge tube and the tube gently stroked until the pellet detached. An additional $20 \mathrm{ml}$ of deionized water was used to clean the tubes inner walls before centrifuging for $10 \mathrm{~min}$ at $4700 \mathrm{~g}$. This rinsing was repeated thrice to rid the HF of SPT before recovering the sample in a glass tray and oven drying at $60^{\circ} \mathrm{C}$ for $24 \mathrm{~h}$. This step produces a 
LF and a HF per size class obtained after step 1. These LF are referred to as free LF (macroaggregate, microaggregate or S\&C-size) and the HF as macroaggregates, microaggregates or free S\&C-size (Figure 2step 2).

\section{iii. Step 3: Macroaggregate breakdown}

This step focused on the HF collected after density fractionation (step 2) of the macroaggregate soil fraction separated from coarse sand size $(2000-250 \mu \mathrm{m})$ material. The purpose of this step was to separate this HF into: Coarse sands, macroaggregate protected fine sands and macroaggregate protected S\&C-size material. To achieve this, the sample was placed in a $250 \mu \mathrm{m}$ sieve in contact with 50 glass beads in a water bath previously installed on a shaker plate. Deionized water was set to run continuously on the sample while maintaining a $2 \mathrm{~cm}$ water front on top. The sample running with the water through the first sieve was collected by means of a funnel and deposited onto a $50 \mu \mathrm{m}$ sieve. This breakdown procedure was set to last for $5 \mathrm{~min}$ on the shaker plate. After this step, deionized water was used to thoroughly rinse the funnel into the $50 \mu \mathrm{m}$ sieve. The $250 \mu \mathrm{m}$ sieve was back-washed and oven dried $\left(60^{\circ} \mathrm{C}\right.$ for $\left.24 \mathrm{~h}\right)$ in a glass tray. Then the wet sieving procedure was repeated for the fraction collected in the $50 \mu \mathrm{m}$ sieve whereby the sieve was tilted and lifted up and down 50 times within two minutes. Again after rinsing the sieve, the reject was back-washed and collected in a glass tray. Both fractions $(250-50 \mu \mathrm{m}$ and $<50 \mu \mathrm{m})$ were collected in glass trays and oven dried $\left(24 \mathrm{~h}\right.$ at $\left.60^{\circ} \mathrm{C}\right)$.

iv. Step 4: Isolating occluded LF and HF

The first purpose of this step was to isolate the non-occluded (non-occ) S\&C-size fraction ( $<50 \mu \mathrm{m})$ contained in macroaggregates from the S\&C-size HF (i.e., S\&C aggregates or free minerals). For this step an adapted density fractionation was undertaken. The sample was submerged in $30 \mathrm{ml} \mathrm{SPT}\left(1.85 \mathrm{~g} \mathrm{~cm}^{-3}\right)$ and gently shaken into suspension. Using an extra $20 \mathrm{ml}$ of SPT the inner walls of the centrifuge tube were rinsed before being centrifuged at $4700 \mathrm{~g}$ for $60 \mathrm{~min}$ (all material bigger than $0.7 \mu \mathrm{m}$ sediments). Using a micropipette, the topmost $15 \mathrm{ml}$ were sampled and deposited on a glass fiber filter $(0.4 \mu \mathrm{m})$ without vacuum application (composes the non-occ LF). After each filtration the filter was rinsed thoroughly to rid it of the SPT and then back-washed in a glass tray to collect the LF in order to avoid filter clogging, this step was repeated thrice. After the third centrifuge, $40 \mathrm{ml}$ of the supernatant were collected and poured in the filter, rinsed thoroughly with distilled water through the filter. Finally, this filter was back-washed to collect the LF in a glass tray.

Next, using SPT, the pellet of the centrifuge tube was shaken into suspension and then dispersed by ultrasonication at $440 \mathrm{~J} \mathrm{ml}^{-1}$ for 2 minutes (Soniprep $150 \mathrm{MSE}$ ) (Amelung and Zech, 1999) in order to break down remaining S\&C-sized aggregates thus freeing the occluded LF. This step was undertaken for, macroaggregate protected S\&C-size material, microaggregates HF and free S\&C-sized material. Following this dispersion, the LF was separated from the HF through a density fractionation $\left(1.85 \mathrm{~g} \mathrm{~cm}^{-3}\right)$ to obtain three new fraction: occluded LF in macroaggregates (occ Mp-LF), occluded LF in microaggregates (occ mp-LF) and occluded LF (occ LF). 
Finally, to conclude step 4, a size separation through wet sieving on the HF obtained following the ultrasonication of microaggregate $\mathrm{HF}$ only is undertaken as described previously to separate fine sands from S\&C size HF.

The density of SPT was controlled before each density fractionation step. Previous studies reported solubilization of organic compounds with SPT use leading to a loss of $\mathrm{C}$ and a decrease the $\mathrm{C}$ recovery after density fractionation (Chenu and Plante, 2006).

The elemental composition ( $\mathrm{C}, \mathrm{H}, \mathrm{N}$ ) was determined via dry combustion for all fractions (LF and HF). The $\mathrm{O}$ concentration was determined on LF only through sample pyrolysis at $1000^{\circ} \mathrm{C}$. The $\mathrm{C}, \mathrm{H}, \mathrm{N}, \mathrm{O}$ concentrations were quantified using a Euro EA elemental analyzer (Hekatech, Germany). Prior to the analysis, $\mathrm{HF}$ samples were acidified with $\mathrm{HCl}$ to remove residual inorganic $\mathrm{C}$.

\subsection{Differential Scanning Calorimetry (DSC)}

We used thermal analysis to compare soil fractions isolated by the fractionation protocol to highlight the presence of PyOM in fractions as well as its position in the OM continuum by comparing CHAR and REF fractions. For this thermal analysis, three out of the five field replicates were selected for each studied soil. For these repetitions, all fractions isolated by the fractionation protocol were analyzed. In addition, three products were characterized as reference materials; hand-picked pyrolyzed OM (hand-picked PyOM, n=3), hand-picked non pyrolyzed coarse OM (hand-picked non-PyOM, $n=3$ ) and freshly pyrolyzed beech ( $F$. Sylvatica -fresh PyOM, n=3). Hand-picked non-PyOM are crop residues hand-picked from REF soils and hand-picked PyOM are charcoal fragments hand-picked from CHAR soils. The freshly pyrolyzed beech was made in an industrial pyrolyzer (Greenpoch SA, Belgium). Finally, three bulk soils were also used as comparison materials $(n=3)$.

Samples were analyzed using a differential scanning calorimeter (Netzsch STA 449, Selb, Germany), Agroscope, Zürich, Switzerland). Before sample analysis the sensor was calibrated for temperature and sensitivity (i.e. reaction enthalpy) with six different standards (indium, tin, bismuth, zinc, aluminium and 305 silver).

Prior to scanning, samples were ground to powder. For HF between 15 and $25 \mathrm{mg}$ of samples were weighed and placed in open $\mathrm{Al}_{2} \mathrm{O}_{3}$ pans for analysis. For $\mathrm{LF}$ only $2 \mathrm{mg}$ of samples were mixed to approximately $18 \mathrm{mg} \mathrm{Al}_{2} \mathrm{O}_{3}$ powder, precise weights were recorded to enable a correction by the dilution factor. Samples were analyzed under a constant flow of $50 \mathrm{ml} \mathrm{min}^{-1}$ synthetic air from $50{ }^{\circ} \mathrm{C}$ to $700{ }^{\circ} \mathrm{C}$ at a heating rate of $20^{\circ} \mathrm{C} \mathrm{min}^{-1}$. During data treatment a baseline correction was applied on thermograms to account for increased heat capacity of samples. Resulting thermograms were drawn between $200-600^{\circ} \mathrm{C}$ to highlight the temperature range of interest as data below $200^{\circ} \mathrm{C}$ or above $600^{\circ} \mathrm{C}$ were never used.

To characterize the material obtained we used values of peak height as the heat flow at a given temperature $\left(\mathrm{W} \mathrm{g}^{-1}\right)$, peak temperatures as the temperature at which main exotherms occur $\left({ }^{\circ} \mathrm{C}\right)$, the area under the curve as the total heat of reaction of a sample $\left(\mathrm{J} \mathrm{g}^{-1}\right)$ delimited by the baseline, and the thermogram $50 \%$ burn-off temperatures $\left({ }^{\circ} \mathrm{C}\right)$ as the temperature where $50 \%$ of the total heat flow has occurred. Finally ratios between areas or peak heights considered as thermally labile or stable were 
used (Leifeld, 2007). In accordance with previous studies, a tipping temperature of $\sim 380-390{ }^{\circ} \mathrm{C}$ was used to differentiate the thermally labile or stable C forms (Dell'Abate et al., 2000; Lopez-Capel et al., 2005).

Amongst various indicators available for the characterization of $C$ forms using DSC, the sum of peak heights of the exotherms $\left(R^{2}=0.78-p\right.$-value $\left.<0.0001\right)$ and the total heat release $\left(R^{2}=0.91-p\right.$-value $<$ $0.0001)$ displayed strong linear correlation with the $C$ content of fractions.

3.5. PyOM and non-PyOM quantification in charcoal rich soils

In CHAR soils, the PyOM was quantified as the additional heat flow occurring in the thermally stable region $\left(>390^{\circ} \mathrm{C}\right.$ ) as opposed to the heat flow in adjacent REF soils. This tipping temperature was established based on our results and in line with previous findings (Dell'Abate et al., 2000; Lopez-Capel et al., 2005). This additional heat flow over the sum of punctual heat flows (peak heights) of CHAR samples multiplied by the samples C content corresponds to the PyOM content of CHAR soils (eq 1 ).

eq 1.

$$
\text { PyOM }=\frac{\sum C H A R_{\text {st.peaks }}-\sum R E F_{\text {st.peaks }}}{\sum C H A R_{\text {peaks }}} * C_{C H A R}
$$

Where PyOM; the PyOM content $\left(\mathrm{g} \mathrm{kg}^{-1}\right)$, st. peaks; the heat flow of exotherms occurring above $390{ }^{\circ} \mathrm{C}$ and $\boldsymbol{C}_{C H A R}$ the $C$ content of CHAR samples.

Changes in non-PyOM contents, $\delta$ (non-PyOM), were calculated as the ratio of differences in CHAR to REF labile peaks height $\left(<390^{\circ} \mathrm{C}\right)$ to the difference in sum of peaks between studied soils, the whole multiplied by the difference of $\mathrm{C}$ content between $\mathrm{CHAR}$ and REF samples (eq 2.).

eq 2.

$$
\delta(\text { non PyOM })=\frac{C H A R_{\text {lab.peak }}-R E F_{\text {lab.peak }}}{\sum C H A R_{\text {peaks }}-\sum R E F_{\text {peaks }}} *\left(C_{C H A R}-C_{R E F}\right)
$$

Where $\boldsymbol{\delta}$ (non-PyOM); the change in non-PyOM content $\left(\mathrm{g} \mathrm{kg}^{-1}\right)$, lab.peak; the heat flow of exotherms occurring below $390^{\circ} \mathrm{C}, \boldsymbol{C}_{C H A R}$ and $\boldsymbol{C}_{R E F}$ the $\mathrm{C}$ content of CHAR and REF samples $\left(\mathrm{g} \mathrm{kg}^{-1}\right)$.

\subsection{Data analysis and signal treatment}

All data analysis, DSC signal treatment and graph plotting were performed using R studio v. 3.4.2 (R Core Team, 2017). Results of all parameters are presented as the means \pm standard deviation (SD). Comparison between fractions of similar density and size class were undertaken by analysis of variances (ANOVA) or by paired t-tests for soil baseline characteristics of bulk soils. Mean classification was pursued through a least significant differences test (LSD-test) and indicated by different letters following mean \pm SD. For the application of this test the normality of the distribution and homoscedasticity of variances was presumed given the low number of repetitions $(n<10)$.

To ensure the validity of our soil fractionation results, the mass recovery and C content (mass by concentration) were calculated at each fractionation step. These were obtained as the sum of fraction masses and $C$ content divided by that of sample used as input for the fractionation step. 


\section{Results}

4.1. Soil characteristics

Beyond the presence of century-old charcoal kiln sites, the study site was selected for its homogeneity (REF soil) in terms of texture (sand $=7.5 \pm 0.4 \%$, silt $=76.9 \pm 0.8 \%$, clay $=15.5 \pm 0.7 \%$ ), C concentration $(1.4 \pm 0.0 \%), \mathrm{CEC}\left(12.0 \pm 0.6 \mathrm{cmol}_{\mathrm{c}} \mathrm{kg}^{-1}\right)$ and $\mathrm{pH}(\mathrm{H} 2 \mathrm{O}-7.8 \pm 0.2)$. On average, $\mathrm{C}$ concentrations in CHAR soils ([1.9-3.3] \%) were $91 \pm 34 \%$ higher than in REF soils $([1.3-1.4] \%)$ (p-val. < 0.01). Similarly, organic N concentrations were $66 \pm 11 \%$ higher ( $p$-val. $<0.001)$ in CHAR $\left([2.1-2.6] \mathrm{g} \mathrm{kg}^{-1}\right)$ than in REF soils ([1.2-1.5] \%). C, N concentrations as well as $\mathrm{C}: \mathrm{N}$ ratios were more variable among replicates in the CHAR soils than in the REF soils. The two studied soils were of identical texture (silty loam) and had similar $\mathrm{pH}$ values. No significant differences in $\mathrm{CEC}$ were reported. Bioavailable $\mathrm{Ca}^{2+}$ concentrations were on average $26 \pm 15 \%$ higher in CHAR soils ( $p$-val. < 0.05) (Table 1 ).

Table 1 - Main bulk soil physico-chemical parameters. Means $\pm S D(n=5)$. When followed by * results are significantly different (p.val in text) according to a student paired T-test.

\begin{tabular}{|c|c|c|}
\hline & CHAR & REF \\
\hline Sand (\%) & $7,7 \pm 0,3$ & $7,5 \pm 0,4$ \\
\hline Silt (\%) & $77,3 \pm 1,1$ & $76,9 \pm 0,8$ \\
\hline Clay (\%) & $15,0 \pm 1,0$ & $15,5 \pm 0,7$ \\
\hline$C(\%)$ & $2,6 \pm 0,5$ & $1,4 \pm 0,0$ \\
\hline Norg ( $(/)$ & $2,3 \pm 0,2$ & $1,4 \pm 0,1$ \\
\hline$C / N(-)$ & $11,3 \pm 1,5$ & $9,9 \pm 0,6$ \\
\hline $\operatorname{CEC}\left(\mathrm{cmolc} \mathrm{kg}^{-1}\right)$ & $14,0 \pm 1,8$ & $12,0 \pm 0,6$ \\
\hline $\mathrm{pH}(\mathrm{H} 2 \mathrm{O})$ & $7,7 \pm 0,2$ & $7,8 \pm 0,2$ \\
\hline $\mathrm{pH}(\mathrm{KCl})$ & $7,0 \pm 0,3$ & $7,1 \pm 0,2$ \\
\hline$P\left(\mathrm{mg} 100 \mathrm{~g}^{-1}\right)$ & $7,3 \pm 0,9$ & $8,0 \pm 0,5$ \\
\hline $\mathrm{K}\left(\mathrm{mg} 100 \mathrm{~g}^{-1}\right)$ & $21,4 \pm 2,9$ & $18,2 \pm 1,1$ \\
\hline $\mathrm{Mg}\left(\mathrm{mg} 100 \mathrm{~g}^{-1}\right)$ & $9,9 \pm 1,0$ & $8,6 \pm 0,7$ \\
\hline $\mathrm{Ca}\left(\mathrm{mg} 100 \mathrm{~g}^{-1}\right)$ & $314,4 \pm 39,1$ & * $251,6 \pm 31,7$ \\
\hline
\end{tabular}

\section{\# Table 1: Main bulk soil physico-chemical parameters.}

\subsection{Weight and Carbon distribution amongst fractions}

In CHAR soils macroaggregates contributed significantly more ( $p$-val. $<0.01)$ to total soil weight than microaggregates or free $S \& C$ fractions $\left(C_{\text {MARRO }}=48.9 \pm 12.8, \mathrm{CHAR}_{\text {MICRO }}=25.5 \pm 8.3, \mathrm{CHAR}_{\text {Free } S \& C}=\right.$

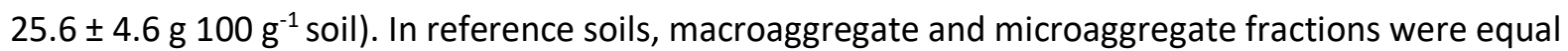
and accounted significantly more to total soil weight $(p$-val. $<0.01)$ than the free $S \& C$ fraction $\left(\right.$ REF $_{\text {MACRO }}=$



The weight recovery following the wet sieving procedure was of $99.4 \pm 0.3 \%$ and $99.6 \pm 0.1 \%$ for CHAR and REF respectively. For step 4 of our fractionation protocol, $93.6 \pm 4.8 \%$ and $89.0 \pm 7.5 \%$ of initial mass were recovered (CHAR and REF respectively). For this step the C content recovery was of $87.9 \pm$ $52.1 \%$ (CHAR) and $100.6 \pm 20.1 \%$ (REF).

Macroaggregate-size free LF was the most abundant free LF in CHAR soils $(0.7 \pm 0.2 \%)$ and was also significantly more abundant ( $p$-val. $<0.05$ ) in CHAR soils than in REF soils (Table 2). Micro and S\&C-size 
free LF displayed similar contribution to the soil mass between the two studied soils (Table 2). Furthermore, free LF displayed systematically higher $C$ contents (i.e., fraction $C$ concentration multiplied by fraction mass) in CHAR soils than in REF soils (Table 2 ) due mainly to higher $\mathrm{C}$ concentrations (i.e., mass of $C$ per mass of the fraction). Macroaggregate size free $L F$ of charcoal rich soils contributed the most to the $\mathrm{C}$ content compared to all other free LF studied soils for both treatments.

While no differences between studied soils were observed, occluded LF contributed more to the total soil weight than free LF (Table 2). In both studied soils, microaggregate-size fractions accounted the most to the total soil $\mathrm{C}$ content for both occluded LF and free LF. Microaggregate size occluded LF stored twice the amount of carbon than microaggregate-size free LF (Table 2).

\# Figure 3: Size class distribution.
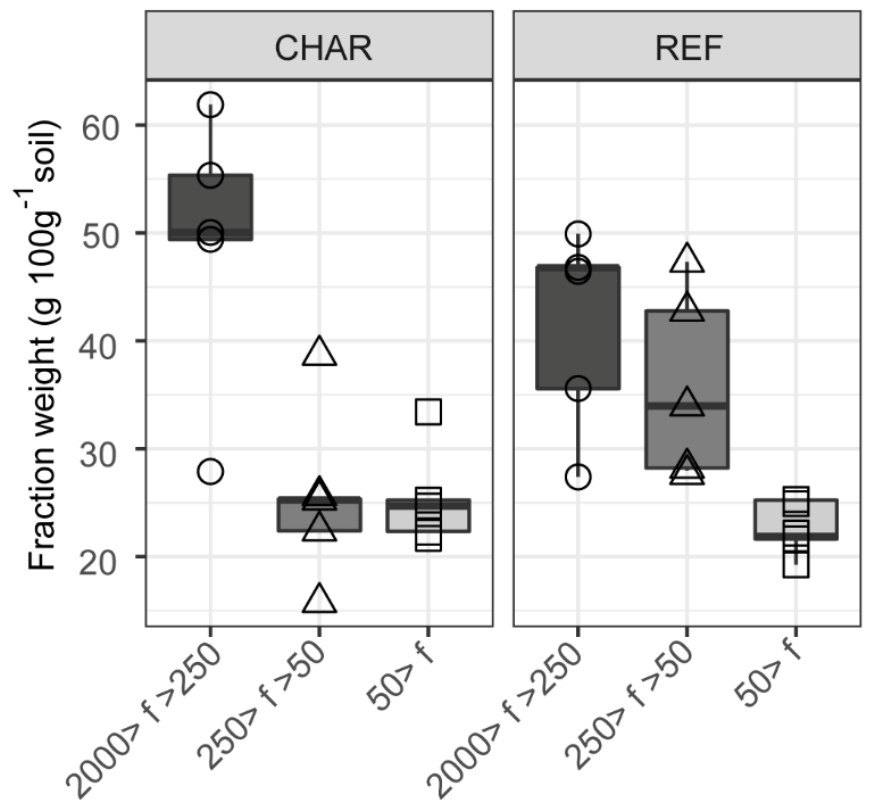

Figure 3 - Size class distribution. Weight distribution amongst fractions of different sizes following wet sieving of the studied soils. Points represent the 5 field replicates. Symbols and box shadings highlight different fraction sizes. Weight recoveries (mean $\pm S D)$ are: $C H A R=99.4 \pm 0.3 \%, R E F=99.6 \pm 0.1 \%$.

The macroaggregate protected HF was significantly more abundant than microaggregate protected and free HF in charcoal rich soils. In reference soils, macroaggregate and microaggregate protected HF, which displayed the same contribution to the total soil mass, were more abundant than free HF (Table 2). The $C$ concentrations of $H F$ ranged between $0.7 \pm 0.2$ to $0.8 \pm 0.2 \%$ in reference soils and from $0.9 \pm$ 0.1 to $1.0 \pm 0.2 \%$ in CHAR soils. In charcoal rich soils, macroaggregate protected HF $\left(3.5 \pm 1.2 \mathrm{~g} \mathrm{~kg}^{-1}\right.$ soil) contributed more to the total soil $\mathrm{C}$ content than microaggregate protected $\mathrm{HF}$ and free $\mathrm{HF}(2.2 \pm 0.6$, $2.2 \pm 0.3 \mathrm{~g} \mathrm{~kg}^{-1}$ soil). In REF soils, macroaggregate and microaggregate protected HF accounted similarly to the total soil $\mathrm{C}$ content, which was a greater contribution than free HF (Table 2).

Summing all fractions regardless of size into either LF or HF showed that although HF accounted for most of the soil mass ( $C H A R=89.0 \pm 2.2, R E F=86.5 \pm 1.0 \%$ ), it merely accounted for $39.0 \pm 25.0 \%$ of the 
recovered soil $\mathrm{C}$ in CHAR soils $\left(\mathrm{CHAR}_{\mathrm{HF}}=7.9 \pm 1.4 \mathrm{~g} \mathrm{C} \mathrm{kg}^{-1}\right)$ and $48.0 \pm 23.0 \%$ in reference soils $\left(\mathrm{REF}_{\mathrm{HF}}=\right.$ $6.8 \pm 1.2 \mathrm{~g} \mathrm{C} \mathrm{kg}^{-1}$ ). In charcoal rich soils, LF (free and occluded combined) comprised $12.2 \pm 3.1 \mathrm{~g} \mathrm{C} \mathrm{kg}^{-1}$ soil of which $6.8 \pm 3.0 \mathrm{~g} \mathrm{C} \mathrm{kg}^{-1}$ soil occurred in occluded LF rather than free LF (5.4 $\pm 0.7 \mathrm{~g} \mathrm{C} \mathrm{kg}^{-1}$ soil). In reference soils, LF combined comprised $7.5 \pm 1.5 \mathrm{~g} \mathrm{C} \mathrm{kg}^{-1}$ soil, mainly as occluded LF ( $R E F_{\text {occ.LF }}=4.7 \pm 1.3 \mathrm{~g}$ $\mathrm{C} \mathrm{kg}^{-1}$ soil) rather than as free $\mathrm{LF}\left(\mathrm{REF}_{\text {freelF }}=2.8 \pm 0.7 \mathrm{~g} \mathrm{C} \mathrm{kg}^{-1}\right.$ soil). $\mathrm{C}$ concentrations of free $\mathrm{LF}$ increased with aggregate size and ranged between $25.6 \pm n a$ and $41.9 \pm 7.4 \%$ for charcoal rich soils and between $10.0 \pm 2.9$ and $36.7 \pm 10.1 \%$ in reference. Microaggregate occluded LF had higher C concentrations for both treatments $(\mathrm{CHAR}=31.1 \pm 5.4, \mathrm{REF}=30.3 \pm 4.2 \%)$ than macroaggregate occluded $\mathrm{LF}$ (CHAR = 26.1 $\pm 2.4, \mathrm{REF}=17.7 \pm 3.4 \%$ ) or S\&C-size occluded LF (CHAR=24.4 $\pm 4.2, \mathrm{REF}=21.3 \pm 2.4 \%)$ (Table 2 ).

Table 2 - Elemental composition of fractions. Mass, C \& N concentration, C \& N content, C: $N$ ratio and PyOM content (mean \pm $S D$ ) distribution amongst fractions as a function of studied soils (CHAR, REF), size and density (LF, HF). Free LF, occluded (occ.) LF and $\mathrm{HF}$ were isolated from the three major aggregate size classes. Different letters indicate significant differences $(p \leq 0.05)$ between studied soils as a function of fraction. " $n a$ " is indicated when not enough fraction mass was recovered for a complete set of analysis. Weight recovery (mean $\pm S D$ ) CHAR $=93.6 \pm 4.8 \%, R E F=89.0 \pm 7.5 \%$. C content recovery CHAR $=87.9 \pm 52.1 \%$, $R E F=100.6 \pm 20.1 \%$.

\begin{tabular}{|c|c|c|c|c|c|c|c|c|c|c|c|c|c|c|c|c|c|c|}
\hline \multirow[t]{2}{*}{ frac. } & \multirow[t]{2}{*}{ soil } & \multirow{2}{*}{$\begin{array}{l}\text { size }(\mu \mathrm{m}) \\
2000-250\end{array}$} & \multicolumn{2}{|l|}{$\begin{array}{c}\text { mass } \\
\left(\mathrm{g} \mathrm{kg}^{-1} \text { soil) }\right.\end{array}$} & \multicolumn{2}{|l|}{$\begin{array}{c}C \\
(\%)\end{array}$} & \multicolumn{2}{|l|}{$\begin{array}{l}\text { Ntot } \\
(\% 0)\end{array}$} & \multicolumn{3}{|c|}{$\begin{array}{c}\mathrm{C} \\
\left(\mathrm{g} \mathrm{kg}^{-1} \text { soil) }\right.\end{array}$} & \multicolumn{2}{|c|}{$\underset{\left(\mathrm{mg} \mathrm{kg}^{-1} \text { soil) }\right.}{\mathrm{N}}$} & \multicolumn{3}{|c|}{$\begin{array}{l}\text { C:N } \\
(-)\end{array}$} & \multicolumn{2}{|c|}{$\begin{array}{c}\text { PyOM } \\
\left(\mathrm{g} \mathrm{kg}^{-1} \text { soil) }\right.\end{array}$} \\
\hline & & & $6,7 \pm 2,0$ & $A$ & $41,9 \pm 7,4$ & $A$ & $15,3 \pm 2,8$ & $A$ & $2,7 \pm$ & 0,4 & $A$ & $98,4 \pm$ & 17,7 & $A$ & $27,5 \pm 3,0$ & A & $1,1 \pm$ & 0,7 \\
\hline \multirow{5}{*}{ free LF } & & $250-50$ & $4,2 \pm 1,5$ & B & $36,5 \pm 4,5$ & A & $14,6 \pm 1,4$ & $A B$ & $1,7 \pm$ & 0,5 & B & $67,2 \pm$ & 18,4 & B & $25,0 \pm 1,5$ & A & $0,3 \pm$ & 0,1 \\
\hline & CHAR & $<50$ & $3,8 \pm 3,3$ & B & $25,6 \pm n$ & ${ }^{4,5}{ }^{n}$ & $11,8 \pm 2,8$ & B & $1,0 \pm$ & \multicolumn{2}{|c|}{ na } & $49,5 \pm$ & 0,0 & $B C D$ & $21,5 \pm n$ & na & $0,1 \pm$ & na \\
\hline & & $2000-250$ & $3,9 \pm 0,7$ & B & $36,7 \pm 10,1$ & A & $14,8 \pm 1,2$ & $A B$ & $1,5 \pm$ & 0,6 & $\mathrm{BC}$ & $58,2 \pm$ & 10,3 & $\mathrm{BC}$ & $25,0 \pm 7,6$ & A & & \\
\hline & REF & $250-50$ & $2,6 \pm 0,8$ & B & $34,9 \pm 3,9$ & $A B$ & $15,5 \pm 2,9$ & $A$ & $1,0 \pm$ & 0,3 & $C D$ & $42,6 \pm$ & 16,0 & $C D$ & $22,8 \pm 2,5$ & A & & \\
\hline & & $<50$ & $3,6 \pm 1,8$ & B & $10,0 \pm 2,9$ & $\mathrm{C}$ & $6,5 \pm 2,2$ & C & $0,3 \pm$ & 0,2 & $\mathrm{D}$ & $22,3 \pm$ & 12,0 & $\mathrm{D}$ & $15,7 \pm 1,8$ & B & & \\
\hline \multirow{6}{*}{ occ. LF } & & $2000-250$ & $7,8 \pm 6,4$ & FG & $26,1 \pm 2,4$ & FG & $17,9 \pm 1,6$ & $\mathrm{GH}$ & $2,1 \pm$ & 1,8 & FG & $142,4 \pm$ & 117,6 & $\mathrm{FG}$ & $14,6 \pm 0,8$ & FG & $1,2 \pm$ & na \\
\hline & & $250-50$ & $11,1 \pm 6,7$ & $\mathrm{~F}$ & $31,1 \pm 5,4$ & $\mathrm{~F}$ & $20,2 \pm 4,7$ & FG & $3,8 \pm$ & 2,3 & $\mathrm{~F}$ & $247,1 \pm$ & 149,6 & $\mathrm{FG}$ & $15,7 \pm 1,5$ & $\mathrm{~F}$ & $0,2 \pm$ & 0,0 \\
\hline & CHAR & $<50$ & $4,2 \pm 0,9$ & FG & $24,4 \pm 4,2$ & G & $15,3 \pm 1,6$ & $\mathrm{H}$ & $1,0 \pm$ & 0,4 & G & $63,3 \pm$ & 18,3 & G & $15,8 \pm 1,6$ & $\mathrm{~F}$ & $0,5 \pm$ & 0,2 \\
\hline & & $2000-250$ & $5.9 \pm 2.4$ & FG & $17,7 \pm 3,4$ & $\mathrm{H}$ & $13,7 \pm 3,1$ & $\mathrm{H}$ & $1.0 \pm$ & 0,5 & G & $82.0 \pm$ & 414 & G & $13,1 \pm 14$ & $\mathrm{GH}$ & & \\
\hline & REF & $250-50$ & $9,1 \pm 1,9$ & FG & $30,3 \pm 4,2$ & $\mathrm{~F}$ & $22,2 \pm 4,4$ & $\mathrm{~F}$ & $2,7 \pm$ & 0,8 & $\mathrm{FG}$ & $\begin{array}{r}02,01 \\
200,2 \pm\end{array}$ & $\begin{array}{l}4,4 \\
60,3\end{array}$ & $\mathrm{FG}$ & $13,9 \pm 1,4$ & $\mathrm{GH}$ & & \\
\hline & & $<50$ & $4,1 \pm 3,5$ & G & $21,3 \pm 2,4$ & $\mathrm{GH}$ & $17,1 \pm 1,9$ & $\mathrm{GH}$ & $0,9 \pm$ & 1,0 & $G$ & $70,1 \pm$ & 72,9 & G & $12,4 \pm 0,7$ & $\mathrm{H}$ & & \\
\hline \multirow{7}{*}{$\mathrm{HF}$} & & $2000-250$ & $414,2 \pm 127,6$ & $\mathrm{~J}$ & $0,9 \pm 0,2$ & $J K$ & $0,9 \pm 0,3$ & J & $3,5 \pm$ & 1,2 & $\mathrm{~J}$ & $403,6 \pm$ & 228,8 & J & $9,8 \pm 2,4$ & $\mathrm{~K}$ & $0,3 \pm$ & 0,2 \\
\hline & & $250-50$ & $221,6 \pm 70,4$ & L & $1,0 \pm 0,2$ & $\mathrm{~J}$ & $0,8 \pm 0,2$ & $\mathrm{JKL}$ & $2,2 \pm$ & 0,6 & $\mathrm{KL}$ & $168,6 \pm$ & 33,4 & $\mathrm{KL}$ & $13,1 \pm 3,2$ & $\mathrm{JK}$ & $0,2 \pm$ & 0,1 \\
\hline & CHAR & $<50$ & $252,1 \pm 56,1$ & $\mathrm{JK}$ & $0,9 \pm 0,1$ & $\mathrm{JK}$ & $0,7 \pm 0,2$ & $\mathrm{JKL}$ & $2,2 \pm$ & 0,3 & $\mathrm{KL}$ & $183,5 \pm$ & 100,7 & $\mathrm{KL}$ & $13,9 \pm 3,3$ & $\mathrm{~J}$ & $0,4 \pm$ & 0,1 \\
\hline & & & & & & & & & & & & & & & & & & \\
\hline & & $2000-250$ & $337,5 \pm 80,5$ & $\mathrm{JK}$ & $0,8 \pm 0,2$ & $\mathrm{~K}$ & $0,9 \pm 0,4$ & JK & $2,7 \pm$ & 1,0 & JK & $306,6 \pm$ & 168,9 & JK & $10,0 \pm 2,8$ & K & & \\
\hline & REF & $250-50$ & $310,7 \pm 79,6$ & $J K L$ & $0,8 \pm 0,1$ & $\mathrm{JK}$ & $0,6 \pm 0,1$ & $\mathrm{KL}$ & $2,6 \pm$ & 0,7 & JK & $178,3 \pm$ & 43,5 & $\mathrm{KL}$ & $14,5 \pm 2,2$ & $J$ & & \\
\hline & & $<50$ & $217,1 \pm 25,0$ & $\mathrm{~L}$ & $0,7 \pm 0,2$ & $\mathrm{~K}$ & $0,5 \pm 0,2$ & L & $1,5 \pm$ & 0,3 & $\mathrm{~L}$ & $109,3 \pm$ & 25,8 & L & $14,0 \pm 1,2$ & $J$ & & \\
\hline \multicolumn{3}{|c|}{ hand-picked PyOM } & \multicolumn{4}{|c|}{$37,8 \pm 7,9$} & $5,4 \pm 1,7$ & & & & & & & & \multicolumn{2}{|l|}{$76,6 \pm 27,4$} & & \\
\hline \multicolumn{3}{|c|}{ fresh PyOM } & & & $79,6 \pm 0,8$ & & $8,8 \pm 0,6$ & & & & & & & & $90,6 \pm 6,9$ & & & \\
\hline
\end{tabular}

\# Table 2: Elemental composition of fractions.

\subsection{Differential Scanning Calorimetry}

422 Three reference materials and two bulk soils were analyzed to allow for the discrimination of various

423 forms of OM (Figure 4). Three distinct exotherms characterized hand-picked PyOM (top-Figure 4) with a 424 major peak at $443 \pm 4{ }^{\circ} \mathrm{C}$. Fresh PyOM was characterized by a single exotherm $\left(485 \pm 2{ }^{\circ} \mathrm{C}\right)$ and a higher 425 punctual heat flow. Hand-picked non-PyOM (crop residues) were characterized by a strong first 426 exotherm occurring at $350 \pm 2{ }^{\circ} \mathrm{C}$ and a second smaller at $430 \pm 1{ }^{\circ} \mathrm{C}$.

427 The total heat flow of CHAR bulk soils were on average $84 \pm 59 \%$ greater than REF bulk soils (Table 4).

428 CHAR bulk soils were characterized by four exotherms occurring at temperatures similar to those 429 occurring in hand-picked PyOM and hand-picked non-PyOM combined (top-Figure 4). Similarly, 
exotherms of reference bulk soils occurred at similar temperatures to those which characterized handpicked non-PyOM.

432 Figure 5 illustrates the thermograms of the three main types of fractions addressed in this study, the 433 free LF, occluded LF and HF (respectively row A, B, C - Figure 5) as a function of the aggregate size class 434 in which they occur (col. 1: macroaggregate, col. 2: microaggregate, col. 3: free S\&C-size - Figure 5).

435 Thermograms of the free LF (Figure 5 - A) showed more pronounced exotherms occurring between 400$500{ }^{\circ} \mathrm{C}$ for CHAR than REF fractions whereas thermograms of REF fractions tended to be more spread out throughout the thermal continuum than CHAR fractions. Nonetheless, $50 \%$ burn-off temperatures were not significantly smaller in REF than CHAR fractions ( $p$-val. >0.05). Finally, a decrease in total heat flow as a function of fraction size was reported whereby heat flows of S\&C-size free LF were significantly smaller $\left(\mathrm{CHAR}=232 \pm 60 \mathrm{~J} \mathrm{~g}^{-1}, \mathrm{REF}=172 \pm 30 \mathrm{~J} \mathrm{~g}^{-1}\right)$ than microaggregate-size free LF (CHAR = $665 \pm 254 \mathrm{~J}$

$\left.441 \mathrm{~g}^{-1}, \mathrm{REF}=753 \pm 160 \mathrm{~J} \mathrm{~g}^{-1}\right)$, and macroaggregate-size free LF (CHAR $\left.=821 \pm 185 \mathrm{~J} \mathrm{~g}^{-1}, \mathrm{REF}=645 \pm 262 \mathrm{~J} \mathrm{~g}^{-1}\right)$

442 regardless of the studied soil ( $p$-val. $<0.01)$. However, total heat flows are equal between fractions when 443 normalized by their $\mathrm{C}$ content.

444 The occluded LF (Figure 5 - B) were characterized by two distinct exotherms visible as individual peaks or 445 marked shoulders occurring between $325-342{ }^{\circ} \mathrm{C}$ and $430-480^{\circ} \mathrm{C}$ for both studied soils (Table 4). In 446 CHAR soils, the second exotherm $\left(430-480^{\circ} \mathrm{C}\right)$ had a higher relative importance as shown by the 447 increase of thermally stable:total peaks ratios by $42.6 \%$ in macroaggregate occluded-LF, $44.3 \%$ in 448 microaggregate occluded-LF and $50.0 \%$ in S\&C-size occluded-LF compared to REF soils (Table 4). No 449 differences in $50 \%$ burn-off temperatures were noted between studied soils within a size class yet 450 macroaggregate protected occluded LF have significantly smaller $50 \%$ burn-off temperatures than 451 microaggregate protected or S\&C occluded LF ( $p$-val. < 0.05 ) (Table 4). 

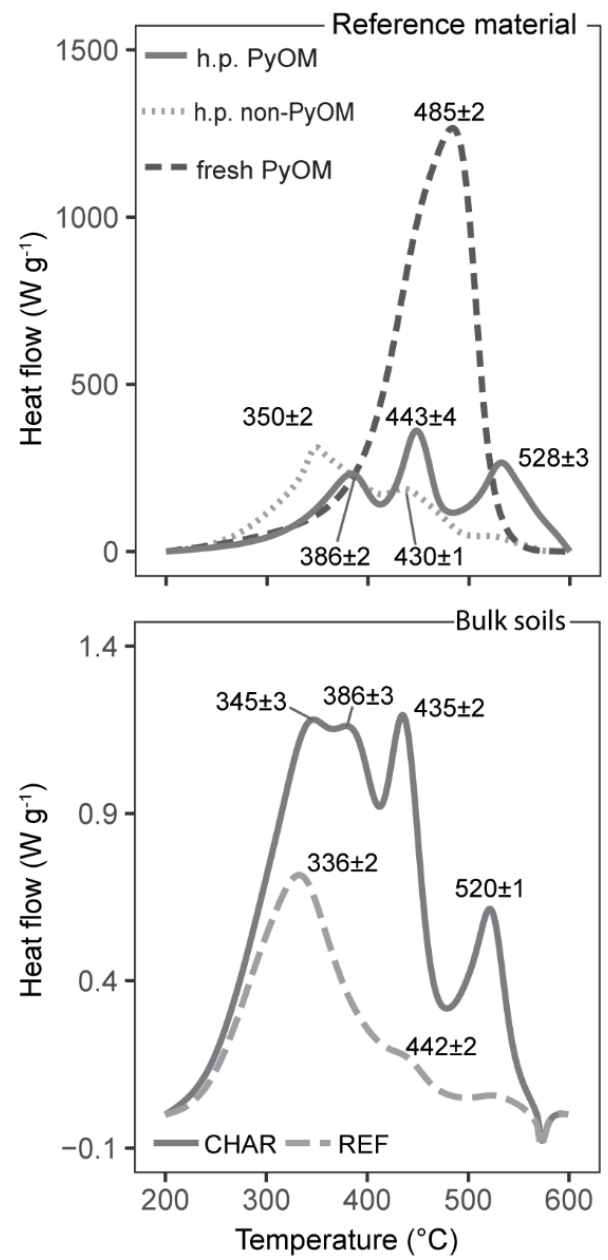

Figure 4-DSC reference curves. DSC thermograms of reference material for the characterization of C forms. Top panel: compares three types of OM forms, hand-picked (abbreviated h.p) non-PyOM, hand-picked PyOM and fresh PyOM. Bottom panel: compares CHAR and REF bulk soils.

$457 \mathrm{HF}$ thermograms were characterized by a main exotherm occurring for both studied soils at $\sim 323^{\circ} \mathrm{C}$. 458 CHAR fractions were differentiated by a marked shoulder in the DSC curves occurring at $\sim 405^{\circ} \mathrm{C}$. Thermograms of HF (Figure $5 \mathrm{C}$ ) were more systematic between repetitions as highlighted by the average heat flow. The average heat flow occurring in HF was of $187.1 \pm 42.3 \mathrm{~J} \mathrm{~g}^{-1}$ for CHAR soils and $147.5 \pm 31.5 \mathrm{~J} \mathrm{~g}^{-1}$ for REF soils where the standard deviation represented respectively 22.5 and $21.3 \%$ of

462 the total heat flow. In occluded LF the average total heat flow was of $356.1 \pm 159.0 \mathrm{~J} \mathrm{~g}^{-1}$ for CHAR and $463242.8 \pm 147.1 \mathrm{~J} \mathrm{~g}^{-1}$ for REF soils with the standard deviation representing 44.6 and $60.6 \%$ for CHAR and 464 REF soils. In free LF, it represented $55.0 \%$ for CHAR samples and $55.5 \%$ in reference samples (CHAR free $\left.465 \mathrm{LF}=495.2 \pm 272.6 \mathrm{~J} \mathrm{~g}^{-1}, \mathrm{REF}_{\text {free } \mathrm{LF}}=523.8 \pm 291.228 \mathrm{~J} \mathrm{~g}^{-1}\right)$. For HF, $50 \%$ burn-off temperatures were always 466 significantly higher for charcoal rich than reference soils ( $p$-val. $<0.01)$ in all size classes and notably 467 smaller than in LFs (Table 4). 
Finally, thermograms differed between hand-picked reference materials (Figure 4) and fractions isolated by the fractionation protocol (Figure 5). Indeed the first $\left(\sim 386 \pm 3^{\circ} \mathrm{C}\right)$ and last $\left(\sim 520-528{ }^{\circ} \mathrm{C}\right)$ exotherms of hand-picked PyOM (Figure 4) were not found in soil fraction thermograms (Figure 5).

\section{\# Figure 5: DSC signatures of soil fractions.}
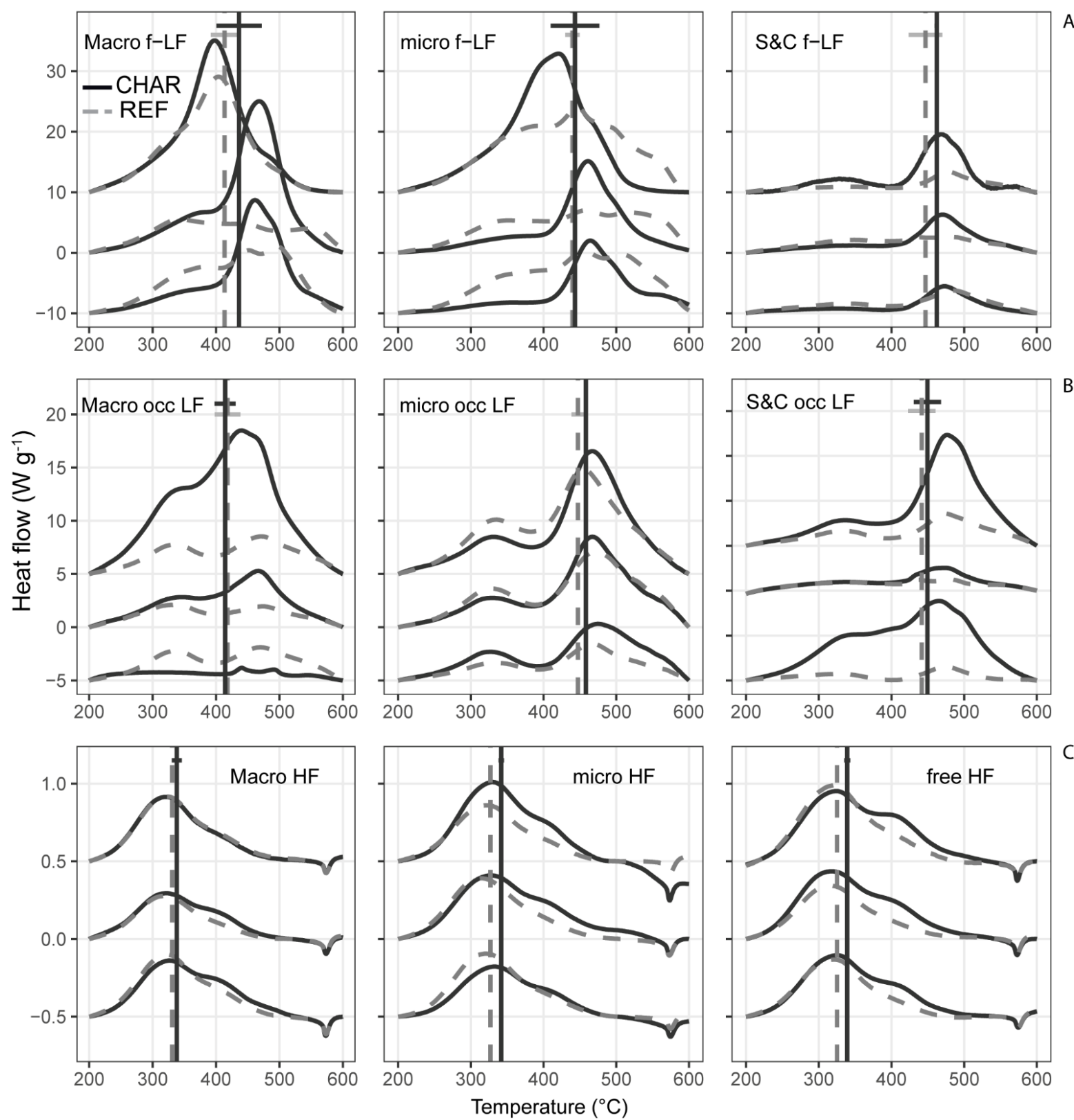

Figure 5 - DSC signatures of soil fractions. Graphs are presented as: free LF (A - top row) either macroaggregate-size (2000-250 $\mu \mathrm{m})$, microaggregate-size (250-50 $\mu \mathrm{m})$ or silt and clay size (50> $\mu \mathrm{m})$. Middle (B) and bottom (C) rows show occluded LF or HF of silt and clay size, either protected in macroaggregates or microaggregates or as free material. In each graph the three replicas were represented, each one was plotted by pair with the adjacent samples of the opposite studied soil (CHAR/REF). Curves were vertically shifted to facilitate the comparison between replicas. Vertical lines show the mean $(n=3) 50 \%$ burn-off temperature 


\subsection{Elemental analyses}

Aged hand-picked PyOM displayed much higher $\mathrm{H}: \mathrm{C}(0.70 \pm 0.10)$ and $\mathrm{O}: \mathrm{C}(0.40 \pm 0.10)$ atomic ratios than fresh PyOM $(\mathrm{H}: \mathrm{C}=0.02 \pm 0.00 ; \mathrm{O}: \mathrm{C}=0.10 \pm 0.00$ ) (Table 3). Differences in $\mathrm{H}: \mathrm{C}$ and $\mathrm{O}: \mathrm{C}$ ratios were greater between soil fractions (free or occluded) than between CHAR and REF soils (Figure 6). Indeed, free LF had lower ratios than occluded LF for both studied soils (Table 3). However, S\&C-size free LF had higher $\mathrm{H}: \mathrm{C}$ and $\mathrm{O}: \mathrm{C}$ ratios in REF soils than in CHAR soils. For occluded $\mathrm{LF}$, differences in $\mathrm{H}: \mathrm{C}$ ratios between studied soils were not significant, and only $\mathrm{O}: \mathrm{C}$ ratios of macroaggregate-size occluded LF were greater in REF fractions than in CHAR fractions.

\# Figure 6: Van Krevelen diagram of fractions.

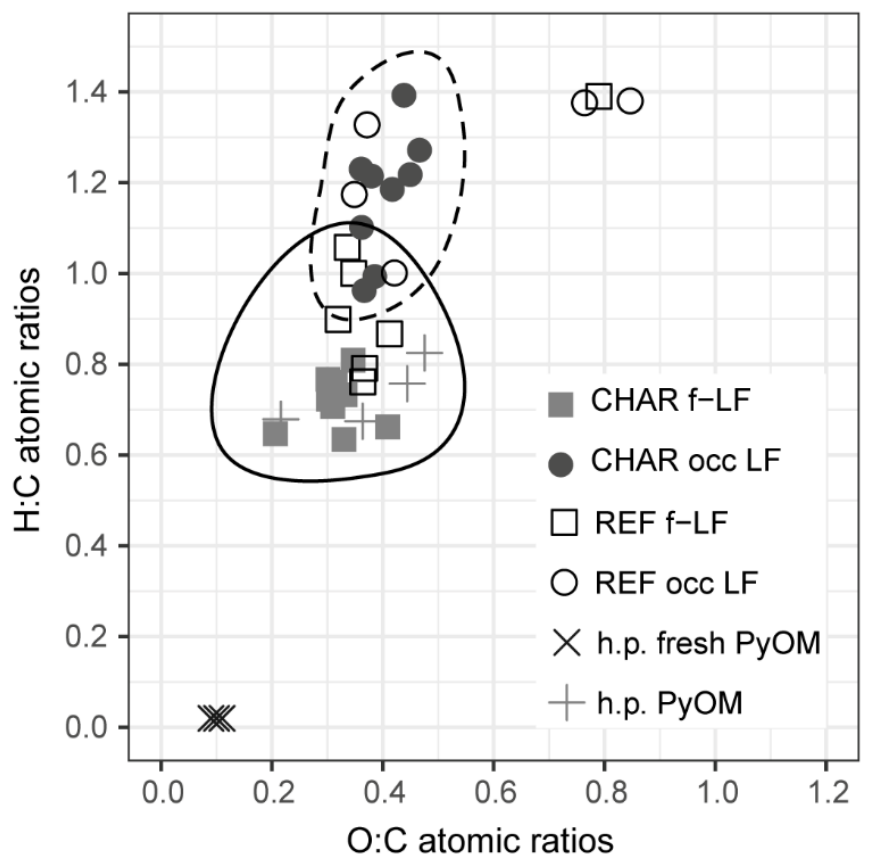

489

490

491

492

493

494

495

496

497

498

499

500

501

Figure 6 - Van Krevelen diagram of fractions. Results show H:C and O:C atomic ratios of LF isolated by the fractionation protocol. Squares illustrate free-LF (f-LF, encircled by solid line) and circles illustrate occluded $L F$ (occ-LF, encircled by dashed line). The point color depends on studied soils, white $=$ REF, grey $=$ CHAR. Crosses show ratios for fresh PyOM or hand-picked PyOM.

$\mathrm{H}: \mathrm{C}$ atomic ratios increased from free $L F$, to occluded $L F$ and $\mathrm{HF}$ for both studied soils (Table 3 ). For microaggregate protected and free $\mathrm{HF}, \mathrm{H}: \mathrm{C}$ ratios were higher in REF (microaggregate protected HF: 3.22 \pm 0.34 , free HF: $4.24 \pm 0.39$ ) than CHAR soils (microaggregate protected HF: $2.71 \pm 0.15$; free HF: $3.44 \pm$ $0.43)$.

Inversely, C:N atomic ratios decreased from free LF ([15.7 $\pm 1.8-27.5 \pm 3.0])$, to occluded LF ([12.4 \pm 0.7 $-15.8 \pm 1.6])$ and HF ([9.8 $\pm 2.4-14.5 \pm 2.2])$. In free $L F, C: N$ ratios decreased as a function of size while their values were similar in occluded LF of the three size classes. Furthermore, $\mathrm{C}: \mathrm{N}$ ratios of HF were lower in macroaggregate protected HF than in microaggregate protected and free HF materials ( $p$-val. < 0.05), for both studied soils (Table 3 ). 
Table 3 - H:C and O:C atomic ratios of soil fractions. Either free LF, occluded LF and HF as a function of treatment and of the size classes in which they were contained. Different letters indicate significant differences $(p \leq 0.05)$ between studied soils as a function of fraction. " $n a$ " indicated that not enough fraction material was recovered for a complete set of analysis. No $0: C$ ratios were measured for mineral dominated fractions.

\begin{tabular}{|c|c|c|c|c|c|c|}
\hline frac. & soil & size $(\mu \mathrm{m})$ & $\begin{array}{c}\mathrm{H}: \mathrm{C} \\
(-)\end{array}$ & & $\begin{array}{c}\text { O:C } \\
(-)\end{array}$ & \\
\hline \multirow{6}{*}{ free LF } & \multirow{4}{*}{ CHAR } & $2000-250$ & $0,69 \pm 0,11$ & C & $0,30 \pm 0,10$ & A \\
\hline & & $250-50$ & $0,72 \pm 0,06$ & C & $0,31 \pm 0,00$ & A \\
\hline & & $<50$ & $0,67 \pm$ & & $0,41 \pm \quad$ na & \\
\hline & & $2000-250$ & $0,95 \pm 0,20$ & B & $0,34 \pm 0,00$ & $A$ \\
\hline & \multirow[t]{2}{*}{ REF } & $250-50$ & $0,75 \pm 0,13$ & C & $0,41 \pm 0,00$ & A \\
\hline & & $<50$ & $1,55 \pm 0,11$ & A & $1,30 \pm 0,50$ & B \\
\hline \multirow{6}{*}{ occ. LF } & \multirow{3}{*}{ CHAR } & $2000-250$ & $1,24 \pm 0,12$ & $\mathrm{~F}$ & $0,39 \pm 0,04$ & G \\
\hline & & $250-50$ & $1,19 \pm 0,20$ & FG & $0,44 \pm 0,03$ & G \\
\hline & & $<50$ & $1,01 \pm 0,12$ & G & $0,38 \pm 0,01$ & G \\
\hline & & $2000-250$ & $1,32 \pm 0,20$ & $\mathrm{~F}$ & $0,85 \pm 0,00$ & $\mathrm{~F}$ \\
\hline & \multirow[t]{2}{*}{ REF } & $250-50$ & $1,31 \pm 0,12$ & $\mathrm{~F}$ & $0,37 \pm 0,00$ & G \\
\hline & & $<50$ & $1,18 \pm 0,14$ & FG & $0,39 \pm 0,05$ & G \\
\hline \multirow{6}{*}{$\mathrm{HF}$} & \multirow{3}{*}{ CHAR } & $2000-250$ & $3,14 \pm 0,37$ & $\mathrm{KL}$ & & \\
\hline & & $250-50$ & $2,71 \pm 0,15$ & L & & \\
\hline & & $<50$ & $3,44 \pm 0,43$ & $\mathrm{KL}$ & & \\
\hline & \multirow{3}{*}{ REF } & $2000-250$ & $3,58 \pm 0,50$ & $\mathrm{~K}$ & & \\
\hline & & $250-50$ & $3,22 \pm 0,39$ & $\mathrm{~K}$ & & \\
\hline & & $<50$ & $4,24 \pm 0,39$ & J & & \\
\hline \multirow{2}{*}{ hand } & d-picked & PyOM & $0,70 \pm 0,10$ & & $0,40 \pm 0,10$ & \\
\hline & resh $\mathrm{PyC}$ & & $0.02 \pm 0,00$ & & $0,10 \pm 0,00$ & \\
\hline
\end{tabular}

\section{\# Table 3: $\mathrm{H}: \mathrm{C}$ and O:C atomic ratios of soil fractions.}

\subsection{Combining analytical practices}

Amongst the different fractions of both studied soils, $\mathrm{H}: \mathrm{C}$ atomic ratios decreased (Table 3 ) alongside an increase in stable:total heat flow ratios (Table 4). HF (i.e., S\&C minerals) were characterized by most of the heat flow occurring at low temperatures as opposed to LF. While $\mathrm{H}: \mathrm{C}$ ratios were similar between studied soils, HF of CHAR soils displayed higher stable:total heat flows than HF of REF soils (CHAR = 24.0 $\pm 3.0, \mathrm{REF}=16.1 \pm 2.5 \%$ ). On average in CHAR soils, free LF showed lower H:C and higher stable:total ratios $(\mathrm{H}: \mathrm{C}=0.69 \pm 0.09$; stable:total $=76.6 \pm 11.1 \%)$ than for occluded $\mathrm{LF}(\mathrm{H}: \mathrm{C}=1.14 \pm 0.16$; stable:total $=68.2 \pm 7.8 \%$ ) whereas in REF soils, average $\mathrm{H}: \mathrm{C}$ ratios for occluded fractions were lower than for free $L F$ (occ LF= $1.27 \pm 0.15$, free $L F=1.08 \pm 0.44$ ) while stable:total ratios were similar (occ $L F=$ $63.2 \pm 4.8$, free $L F=64.1 \pm 6.2 \%)($ Table 4$)$ 
519 Charcoal rich bulk soils contained between 5.8 and $11.9 \mathrm{~g} \mathrm{~kg}^{-1}$ soil of PyOM. This amounts for between $520 \quad 29.9$ and $41.3 \%$ of the total SOC in bulk CHAR soils. In free LF, the PyOM accounted between 13.7 and $52141.2 \%$ of the total SOC in these fraction. Most of the PyOM was found as macroaggregate-size free LF 522 and accounted for up to $1.1 \pm 0.7 \mathrm{~g} \mathrm{~kg}^{-1}$ soil (Table 2). Similar amounts of PyOM were found in occluded 523 LF and accounted between 5.4 and $55.9 \%$ of total SOC contained in occluded fractions. HF contained 524 between $0.2 \pm 0.1$ and $0.4 \pm 0.1 \mathrm{~g} \mathrm{~kg}^{-1}$ soil of PyOM. This represented between 7.3 and $16.2 \%$ of the SOC 525 contained in $\mathrm{HF}$ and was highest for free $\mathrm{HF}\left(0.4 \pm 0.1 \mathrm{~g} \mathrm{~kg}^{-1}\right.$ soil).

526 A higher heat of reaction occurring at thermally labile temperatures in CHAR soils than REF soils show 527 that differences in C content did not solely occur as thermally stable OM but also as labile PyOM or non528 PyOM. Bulk charcoal rich soils accounted 0.4 to $2.3 \mathrm{~g} \mathrm{C} \mathrm{kg}^{-1}$ soil of additional thermally labile OM 529 compared to reference soils. This represented between 5.8 and $16.2 \%$ of the additional $C$ content of 530 CHAR soils. The combined heat flows of occluded LF were on average $38.7 \%$ higher in CHAR than REF 531 fractions $\left(\mathrm{CHAR}_{\mathrm{occ}}=9.8 \pm 4.3 \mathrm{~W} \mathrm{~g}^{-1}, \mathrm{REF}_{\mathrm{occ}}=7.1 \pm 1.8 \mathrm{~W} \mathrm{~g}^{-1}\right)$ although non-significantly different due to 532 the variability between CHAR repetitions. However, an increase in thermally labile peak height was not 533 systematic between samples and hence not statistically significant for occluded LF ( $p$-val. > 0.05) nor HF 534 (p-val. > 0.05).

Table 4 - DSC curve characteristics of soil fractions. 50 \% burn-off T, peak $T$ and heat flows of visible exotherms as well as ratios between labile:total and stable:total heat flow (mean $\pm S D$ ) are represented followed by results of analysis of variance. For a given fraction (frac.) identical letters indicate equal means.

\begin{tabular}{|c|c|c|c|c|c|c|c|c|c|c|c|c|c|c|c|c|}
\hline \multirow{3}{*}{$\begin{array}{c}\text { frac. } \\
\text { free LF }\end{array}$} & \multirow{3}{*}{$\begin{array}{c}\text { soil } \\
\text { CHAR }\end{array}$} & \multirow{3}{*}{$\begin{array}{l}\text { size }(\mu \mathrm{m}) \\
2000-250\end{array}$} & \multirow{2}{*}{\multicolumn{2}{|c|}{$\begin{array}{c}50 \% \text { Burnoff T } \\
\left({ }^{\circ} \mathrm{C}\right)\end{array}$}} & \multicolumn{3}{|c|}{ exotherm 1} & & \multicolumn{3}{|c|}{ exotherm 2} & & & & & \\
\hline & & & & & \multicolumn{2}{|l|}{$\begin{array}{c}\text { peak T } \\
\left({ }^{\circ} \mathrm{C}\right)\end{array}$} & \multicolumn{2}{|l|}{$\begin{array}{l}\text { Heat flow } \\
\left(\mathrm{W} \mathrm{g}^{-1}\right)\end{array}$} & $\begin{array}{c}\text { peak T } \\
\left({ }^{\circ} \mathrm{C}\right)\end{array}$ & \multicolumn{2}{|r|}{$\begin{array}{l}\text { Heat flow } \\
\left(\mathrm{W} \mathrm{g}^{-1}\right)\end{array}$} & \multicolumn{3}{|c|}{$\begin{array}{l}\text { Labile : Total } \\
\text { Heat flow }(\%)\end{array}$} & \multicolumn{2}{|c|}{$\begin{array}{l}\text { Stable : Total } \\
\text { Heat flow (\%) }\end{array}$} \\
\hline & & & $436,3 \pm 35,9$ & $A B$ & & & & & $442,3 \pm 38,6$ & $A$ & $22,9 \pm 3,7$ & A & $28,5 \pm 15,2$ & $B C$ & $72,0 \pm 14,9$ & $A B$ \\
\hline & & $250-50$ & $443,3 \pm 33,5$ & $A B$ & & & & & $448,7 \pm 24,0$ & A & $16,7 \pm 5,6$ & $A B$ & $24,2 \pm 13,3$ & $\mathrm{C}$ & $76,2 \pm 13,0$ & A \\
\hline & & $<50$ & $462,3 \pm 3,1$ & A & & & & & $471,0 \pm 2,0$ & A & $6,8 \pm 2,6$ & C & $22,6 \pm 1,0$ & C & $77,5 \pm 1,0$ & A \\
\hline & REF & $2000-250$ & $413,5 \pm 21,9$ & B & & & & & $442,3 \pm 38,6$ & A & $11,0 \pm 7,3$ & $\mathrm{BC}$ & $41,2 \pm 7,5$ & B & $59,3 \pm 7,4$ & B \\
\hline & & $250-50$ & $439,8 \pm 9,9$ & $A B$ & & & & & $454,0 \pm 6,2$ & A & $10,5 \pm 3,5$ & $\mathrm{BC}$ & $32,4 \pm 2,4$ & $\mathrm{BC}$ & $67,9 \pm 2,4$ & $A B$ \\
\hline & & $<50$ & $446,8 \pm 23,2$ & $A B$ & & & & & $483,0 \pm 4,4$ & A & $3,2 \pm 0,6$ & C & $34,0 \pm 6,2$ & $\mathrm{BC}$ & $66,2 \pm 6,2$ & $A B$ \\
\hline \multirow[t]{6}{*}{ occ. LF } & CHAR & $2000-250$ & $414,3 \pm 16,6$ & G & $335,0 \pm 1,4$ & $\mathrm{~F}$ & $3,8 \pm 3,7$ & $\mathrm{~F}$ & $449,7 \pm 15,0$ & G & $6,7 \pm 6,3$ & $\mathrm{~F}$ & $40,8 \pm 6,7$ & FG & $59,5 \pm 6,8$ & $\mathrm{GH}$ \\
\hline & & $250-50$ & $458,3 \pm 2,0$ & $F$ & $328,7 \pm 1,5$ & $\mathrm{H}$ & $3,0 \pm 0,4$ & $\mathrm{~F}$ & $469,7 \pm 4,6$ & $\mathrm{~F}$ & $8,5 \pm 3,1$ & $\mathrm{~F}$ & $26,6 \pm 2,8$ & $\mathrm{H}$ & $73,6 \pm 2,8$ & $\mathrm{~F}$ \\
\hline & & $<50$ & $449,5 \pm 18,8$ & $F$ & $342,0 \pm 0,0$ & $\mathrm{~F}$ & $3,0 \pm 2,1$ & $\mathrm{~F}$ & $472,3 \pm 5,7$ & $\mathrm{~F}$ & $7,9 \pm 5,0$ & $\mathrm{~F}$ & $28,7 \pm 7,0$ & $\mathrm{H}$ & $71,5 \pm 6,9$ & $\mathrm{~F}$ \\
\hline & REF & $2000-250$ & $418,0 \pm 20,2$ & G & $335,0 \pm 1,4$ & $\mathrm{~F}$ & $2,5 \pm 0,4$ & $\mathrm{~F}$ & $471,7 \pm 1,2$ & $\mathrm{~F}$ & $2,9 \pm 0,8$ & $\mathrm{~F}$ & $42,8 \pm 5,4$ & $\mathrm{~F}$ & $57,5 \pm 5,4$ & $\mathrm{H}$ \\
\hline & & $250-50$ & $447,3 \pm 8,8$ & $F$ & $332,0 \pm 4,0$ & G & $3,5 \pm 1,7$ & $\mathrm{~F}$ & $464,3 \pm 8,3$ & $\mathrm{~F}$ & $6,8 \pm 3,2$ & $\mathrm{~F}$ & $31,7 \pm 1,5$ & $\mathrm{GH}$ & $68,5 \pm 1,5$ & FG \\
\hline & & $<50$ & $441,7 \pm 18,9$ & FG & $342,0 \pm 0,0$ & $\mathrm{~F}$ & $1,1 \pm 0,5$ & $\mathrm{~F}$ & $475,7 \pm 4,0$ & $\mathrm{~F}$ & $2,1 \pm 1,3$ & $\mathrm{~F}$ & $38,8 \pm 6,2$ & FG & $61,4 \pm 6,2$ & $\mathrm{GH}$ \\
\hline \multirow[t]{6}{*}{ HF } & CHAR & $2000-250$ & $338,2 \pm 7,8$ & JK & $324,0 \pm 1,7$ & $\mathrm{~K}$ & $0,4 \pm 0,1$ & $J$ & $405,0 \pm 0,0$ & & $0,2 \pm 0,0$ & JKL & $76,9 \pm 4,6$ & $\mathrm{KL}$ & $23,5 \pm 4,6$ & JK \\
\hline & & $250-50$ & $341,8 \pm 3,8$ & $\mathrm{~J}$ & $329,7 \pm 2,1$ & $\mathrm{~J}$ & $0,4 \pm 0,1$ & J & $405,0 \pm 0,0$ & & $0,2 \pm 0,0$ & JK & $77,0 \pm 4,2$ & $\mathrm{KL}$ & $23,4 \pm 4,2$ & JK \\
\hline & & $<50$ & $339,2 \pm 4,2$ & J & $322,0 \pm 4,4$ & $\mathrm{~K}$ & $0,4 \pm 0,0$ & $J$ & $405,0 \pm 0,0$ & & $0,2 \pm 0,0$ & $\mathrm{~J}$ & $75,3 \pm 2,2$ & $\mathrm{~L}$ & $25,1 \pm 2,2$ & $\mathrm{~J}$ \\
\hline & REF & $2000-250$ & $330,8 \pm 3,4$ & $\mathrm{KL}$ & $322,3 \pm 1,5$ & $\mathrm{~K}$ & $0,4 \pm 0,1$ & J & $405,0 \pm 0,0$ & & $0,2 \pm 0,0$ & $\mathrm{KL}$ & $81,7 \pm 2,7$ & $\mathrm{JK}$ & $18,6 \pm 2,7$ & $\mathrm{KL}$ \\
\hline & & $250-50$ & $327,0 \pm 2,6$ & $\mathrm{KL}$ & $319,0 \pm 3,6$ & $\mathrm{~K}$ & $0,4 \pm 0,0$ & $\mathrm{~J}$ & $405,0 \pm 0,0$ & & $0,1 \pm 0,0$ & L & $85,3 \pm 1,2$ & $\mathrm{~J}$ & $15,1 \pm 1,2$ & $\mathrm{~L}$ \\
\hline & & $<50$ & $325,2 \pm 2,6$ & $\mathrm{KL}$ & $319,3 \pm 3,8$ & $\mathrm{~K}$ & $0,4 \pm 0,1$ & $J$ & $405,0 \pm 0,0$ & & $0,1 \pm 0,0$ & L & $85,6 \pm 1,6$ & $\mathrm{~J}$ & $14,7 \pm 1,6$ & $\mathrm{~L}$ \\
\hline
\end{tabular}




\section{Discussion}

5.1. Physico-chemical characteristics of charcoal rich soils

Our results show close to a twofold increase in $\mathrm{C}$ contents as a result of century-old PyOM accumulation in cultivated soils as previously reported for similar sites (Hernandez-Soriano et al., 2016b; Kerré et al., 2016; Hardy et al., 2017a). As both studied soils were sampled in the same field, they have received similar amendments and field works in identical climatic conditions. We can therefore be confident such an increase in $\mathrm{C}$ content is induced by the presence of PyOM and corresponds to increases in both PyOM and non-PyOM contents in kiln soils. Accumulation of non-PyOM in kiln soils have been previously shown to originate from a decreased mineralization rates of recent non-PyOM (Hernandez-Soriano et al., 2016a; Kerré et al., 2016) and from the adsorption of dissolved organic compounds onto charcoal particles (Hernandez-Soriano et al., 2016b; Kerré et al., 2017). A relative greater aboveground biomass production on kiln soils (Heidarian Dehkordi et al., 2020) may also be responsible for a positive feedback loop through an increase in non-PyOM inputs to the charcoal rich soils.

Previous studies on similar kiln sites in Wallonia reported significant increases in CEC related to the presence of charcoal (Kerré et al., 2016; Hardy et al., 2017a). Our results show slight yet non-statistically significant increases. Furthermore, higher CEC has been estimated for century-old PyOM fragments ( $P y O M=414 \mathrm{cmol}_{\mathrm{c}} \mathrm{kg}^{-1}$ ) compared to non-PyOM (non-PyOM $=213 \mathrm{cmol}_{\mathrm{c}} \mathrm{kg}^{-1}$ ) explained by an increase in the amounts of functional groups with charcoal ageing and cultivation combined with the high specific surface area of PyOM (Hardy et al., 2017a). Additionally, CHAR soils displayed greater bioavailable $\mathrm{Ca}^{2+}$ contents than adjacent REF soils as previously reported (Hardy et al., 2017a, 2017b). Increased Ca ${ }^{2+}$ contents in CHAR soils result from the high affinity between $\mathrm{Ca}^{2+}$ and carboxylate groups found on aged PyOM thus potentially serving as a mediator for PyOM interaction with soil constituents (Kalinichev and Kirkpatrick, 2007).

\subsection{Element $\mathrm{C}: \mathrm{N}, \mathrm{H}: \mathrm{C}$ and $\mathrm{O}: \mathrm{C}$ ratios support charcoal-induced organo-mineral associations} The presence of PyOM in charcoal enriched soils resulted in a greater macroaggregate formation at the expense of free microaggregates in comparison to reference soils. Macroaggregate turnover is known to be relatively rapid particularly in cropped ecosystems where tillage damages soil structure (Six et al., 2000; Chenu et al., 2019). In CHAR soils, where macroaggregates are more abundant than in REF soils, it is likely that PyOM acts as an additional binding agent between soils constituents and microaggregates (Six et al., 2000). Furthermore, a larger macroaggregate fraction in CHAR soils may also result from higher aggregate stability (Pituello et al., 2018) caused by increased inter-particular cohesion (Sun and Lu, 2014) or faster aggregate formation as a result of the specific surface area of PyOM. Century-old PyOM therefore improves soil aggregation which is a key property for soil structure, essential in maintaining soil fertility and which may also further increase the stability of OM through increased physical disconnection with decomposers (Schmidt et al., 2011; Lehmann and Kleber, 2015).

Our results showed significant differences in $\mathrm{O}: \mathrm{C}$ and $\mathrm{H}: \mathrm{C}$ ratios between free and occluded LF for both studied soils thereby showing that the position of PyOM and non-PyOM in the soil matrix and their chemical composition are strongly linked. Lower $\mathrm{O}: \mathrm{C}$ and $\mathrm{H}: \mathrm{C}$ atomic ratios suggest a greater abundance of large aromatic structures in free LF than in occluded LF whereas the latter may be enriched in either 
PyOM with more functional entities such as carboxyl groups or additional non-PyOM (Brodowski et al., 2005; Cheng et al., 2008a).

Long-term residence of PyOM in soils results in higher $\mathrm{O}: \mathrm{C}$ and $\mathrm{H}: \mathrm{C}$ atomic ratios (Cheng et al., 2008a; Nguyen et al., 2008; Hardy et al., 2017b) compared to fresh PyOM (Hardy et al. 2017b). Ageing of PyOM is known to occur mainly through oxidation of the particles and results in the development of phenol, carboxyl and carbonyl functional groups on the PyOM aromatic structures (Cheng et al., 2008a). Although free LF are highly weathered compared to fresh PyOM, their lower $\mathrm{H}: \mathrm{C}$ and O:C ratios in comparison to occluded LF suggests free LF may be less oxidized than occluded LF. In turn, this higher functionalization of PyOM in occluded LF compared to free LF supports its increased reactivity towards surrounding soil constituents. As all the PyOM in CHAR soils is of similar age range and as most of the oxidation occurs rapidly following the addition of PyOM to the soil, it is expected that particles would have faced similar oxidative agents (Nguyen et al., 2008). Therefore, differences in O:C and $\mathrm{H}: \mathrm{C}$ ratios between free and occluded LF may originate from products with varying initial properties. Indeed, slight changes in pyrolysis conditions throughout the kiln during charcoal production may result in varying degrees of aromaticity or aromatic condensation (B. P. Singh et al., 2012; Wiedemeier et al., 2015) resulting in different degrees of hydroxylation and carboxylation (Lehmann et al., 2005) and in turn leading to charcoal fragments of varying persistence. However, it may be that when first produced, the PyOM was physically and chemically homogeneous in composition and that, with time and farming practices, the PyOM fragments were broken down to different size classes which resulted in different degrees of oxidation. In addition, higher $\mathrm{H}: \mathrm{C}$ and $\mathrm{O}: \mathrm{C}$ atomic ratios of occluded LF than free LF in charcoal enriched soils may also originate from higher amounts of non-PyOM such as microbial related biomass (Lehmann et al., 2011) or stabilized fresh non-PyOM residues (Hernandez-Soriano et al., 2016a). In $\mathrm{HF}$, differences in $\mathrm{H}: \mathrm{C}$ and $\mathrm{O}: \mathrm{C}$ ratios result either from mineral phases or changes in $\mathrm{OM}$. However, as texture and mineralogy are similar throughout the study site, differences in $\mathrm{H}: \mathrm{C}$ and $\mathrm{O}: \mathrm{C}$ ratios between studied soils are mainly attributed to the presence of PyOM. Lower $\mathrm{H}: \mathrm{C}$ ratios in $\mathrm{HF}$ of charcoal enriched soils than in reference soils demonstrate the presence of PyOM (C-rich) associated with minerals through S\&C-size microaggregation or adsorption.

Similar $\mathrm{C}: \mathrm{N}$ ratios between studied soils, despite generally higher $\mathrm{C}$ content in $\mathrm{CHAR}$, indicate that larger amounts of $\mathrm{N}$ occur in charcoal enriched soils than in adjacent REF soils. This may result from significantly higher nitrate contents retained by the biochar (Hagemann et al., 2017) or N-rich organic compounds derived from root and microbial activities (Brodowski et al., 2005; Meier et al., 2017). Indeed, microbial-derived proteins and root exudates are known to strongly bind to minerals with possibilities for their polar chains to serve as binding sites (Kleber et al., 2007; Vogel et al., 2014; Poirier et al., 2018) and to interact with PyOM (Brodowski et al., 2005). In HF this is supported by C:N ratios similar to those expected for microbial-derived OM sorbed onto mineral surfaces ranging [7-14] (Aufdenkampe et al., 2001; Bell et al., 2014).

\subsection{Thermal analysis confirms organo-mineral associations}

The presence of charcoal in the bulk soil of kiln sites is distinguished from reference soils by three distinct exotherms (Figure 4). These exotherms occur at higher temperatures than in reference thermograms and correspond to peak temperatures characterizing hand-picked charcoal particles 
(Hardy et al., 2017a). At first, fresh PyOM is characterized by a single sharp exotherm. With time, as the PyOM particle oxidizes from its surface inwards (Brodowski et al., 2005; Cheng et al., 2008a) the aromatic structures are broken down and functional groups appear (Plante et al., 2009). The occurrence of these functional groups decreases the thermal stability of PyOM as shown by the occurrence of a new exotherm at $386^{\circ} \mathrm{C}$ (Figure 4), which corresponds to the combustion of O-rich compounds (Hardy et al., 2017b). Hardy et al. (2017b) suggested that $\mathrm{Ca}^{2+}$ acted as a thermal catalyst thereby resulting in a decrease of thermal stability of functional groups visible in thermograms as a decrease in peak temperatures towards more thermally labile OM. Interestingly, hand-picked PyOM is characterized by the occurrence of a third peak $\left(\sim 528^{\circ} \mathrm{C}\right)$ with higher thermal stability (Figure 4 ) than fresh PyOM as previously reported by Hardy et al. (2017b). In this study authors showed an increase in this peak height with time of cultivation thereby suggesting that amounts of highly thermally stable $\mathrm{C}$ increase relatively to other, less stable forms which are preferentially altered or lost from the system. The third type of OM used as a reference curve is hand-picked non-PyOM which is characterized by the occurrence of both thermally labile $\left(336 \pm 2{ }^{\circ} \mathrm{C}\right)$ and thermally stable $\left(442 \pm 2{ }^{\circ} \mathrm{C}\right) \mathrm{OM}$ (Figure 4). These peak temperatures correspond to those of cellulose and lignin like molecules (Lopez-Capel et al., 2005). The occurrence of these exotherms in both studied soils highlight that PyOM in soils can be determined as the additional heat flow occurring at thermally stable temperatures in CHAR as opposed to REF soils.

In both studied soils, LF (i.e. occ. or free) are characterized by higher thermal stability than HF. Free LF in CHAR soils are characterized by a punctual heat flow comparable to that of pristine fresh PyOM which suggests little functionalization of PyOM particles in these fractions. Such a recalcitrance to oxidation for CHAR free LF is explained by a greater aromaticity or degree of condensation of the PyOM (Wiedemeier et al., 2015). Thermograms of REF free LF on the other hand show more diversity in the type of OM composing the fraction as shown by a multitude of peaks. In agricultural soils, after biomass inputs, it may be expected that free LF would be quickly deprived of small and energy rich forms of OM due to rapid mineralization of thermally labile organic compounds more beneficial to decomposers (Leifeld, 2008; Rovira et al., 2008; Barré et al., 2016). As a result, following the preferential decomposition of energy rich OM, free LF in CHAR soils are expected to be dominated by larger more persistent molecules with higher binding energy and hence to be thermally more stable (Leinweber et al., 1992; Lopez-Capel et al., 2005; De la Rosa et al., 2008). This is supported by higher $50 \%$ burn-off temperatures in free LF compared to other fractions (Leifeld, 2008)(Figure 5).

Occluded LF differ from free LF through the appearance of a second class of exotherms occurring around $\sim 330^{\circ} \mathrm{C}$ (Figure 5). The occurrence of this thermally labile peak suggests an accumulation of energy-rich $\mathrm{OM}$ resulting from physical inaccessibility of this $\mathrm{OM}$ to decomposers and organo-mineral associations (Lehmann and Kleber, 2015). In occluded LF of REF soils significant heat flows occur at high thermal stability. These exotherms coincide with peak temperatures attributed to PyOM (Figure 5) which complicates a definite distinction between PyOM and non-PyOM (Leifeld, 2007). Such exotherms highlight the importance of studying CHAR soils in comparison to thermograms of REF soils to determine the PyOM pool as the additional heat flow occurring in CHAR soils. In CHAR occluded LF the presence of PyOM is mainly underlined by a slightly higher $50 \%$ burn-off temperatures (Figure 5 ) and higher stable:total heat flow ratios (Table 4). 
In $\mathrm{HF}$ the presence of an elbow occurring at $\sim 410^{\circ} \mathrm{C}$ in $\mathrm{CHAR}$ and not in REF soils strongly suggests the presence of PyOM tightly associated with minerals. Indeed, although these fractions are dominated by thermally labile OM (Figure $5-\mathrm{C}$ - peaks $\sim 330^{\circ} \mathrm{C}$ ), the sustained presence of PyOM in fractions dominated by microaggregation and adsorption suggests that century-old charcoal displays strong interactions with soil minerals (Chenu and Plante, 2006; Virto et al., 2010). The decrease in peak temperatures of PyOM originates from the creation of phenol, carbonyl and carboxyl functionalities at the surface of century-old charcoal particles (Hardy et al., 2017a). Our results support this assumption as this peak value in $\mathrm{HF}$ corresponding to PyOM $\left(\sim 410^{\circ} \mathrm{C}\right)$ occurs between the two first peaks of handpicked PyOM ( $\mathrm{p} 1=386 \pm 2{ }^{\circ} \mathrm{C}, \mathrm{p} 2=443 \pm 4{ }^{\circ} \mathrm{C}$ ). Furthermore, because functional groups are needed for sorption to occur (Kleber et al., 2015) it is expected that PyOM particles tightly bound to mineral phases have been strongly oxidized through either biotic or abiotic processes (Cheng et al., 2006). As microaggregation and adsorption are the main stabilization mechanisms for OM in soils, it is expected that beyond its chemical recalcitrance, PyOM is further stabilized by organo-mineral associations (von Lützow et al., 2006; Dungait et al., 2012; Lehmann and Kleber, 2015) yet that this additional physical protection is not discernable by thermal analyses (Plante et al., 2011).

\subsection{A major part of PyOM is associated with mineral phases}

DSC results show PyOM amounts for an important part of the total SOC [29.9 - $41.3 \%$ ] in bulk charcoal rich soils. Due to the variability in chemical composition of PyOM no single method can correctly quantify it (Lorenz and Lal, 2014; Kerré et al., 2016). Our methodology consisted in estimating the amount of PyOM by comparing peak height ratios between CHAR and adjacent REF soil with respect to differences in $\mathrm{C}$ content and is therefore not a direct quantification. Furthermore, our quantification approach is developed on the assumption that no PyOM is found in REF soils. However, it may be expected that small amounts of PyOM could be found in reference soils suggesting PyOM amounts are slightly underestimated in charcoal rich soils. Using standard additions of PyOM to mineral soils free of PyOM, Hardy et al., (2017a) reported that charcoal-C content in kiln sites amounts for $79.5 \%$ of the difference in $\mathrm{C}$ content between CHAR soils and REF soils. Using this relationship on our charcoal rich soils we obtain an estimate of PyOM content ranging [25.3 - 39.2\%], slightly lower than our estimate [29.9 - 41.3\%]. Using DSC on isolated soil fractions enabled an understanding of the distribution of PyOM amongst soil fractions. Results show that after two centuries of residence in soils, PyOM is located in all soil fractions and that, although a large amount occurred as free LF $(43.6 \pm 22.9 \%$ of total PyOM), the majority interacts with mineral phases (56.4 $\pm 22.9 \%$ of total PyOM) through occlusion (29.6 $\pm 28.8 \%$ of total PyOM) or sorption (26.78 $\pm 5.9 \%$ of total PyOM) to mineral phases (Table 2$)$.

Despite decades of incorporation in the soil matrix and sustained farming practices, results show that a large amount of PyOM is still found as free LF in CHAR soils. This result illustrates the importance of PyOM composition for its stability in soils and the role of charring against oxidative agents through its polycondensed aromatic structure (Wiedemeier et al., 2015) and against decomposers by making it a hardly decomposable form of OM (Rovira et al., 2008; Wang et al., 2016). Nonetheless, in the presence of specific decomposers, PyOM may decompose faster than often reported (Hamer et al., 2004). Recent studies show that the persistence of PyOM in soils may be overestimated (Hammes et al., 2008; N. Singh et al., 2012; Lehndorff et al., 2014; Lutfalla et al., 2017). Nonetheless, given the high temperatures and 
low oxygen contents found in kiln sites, it may be expected that the stability of the charcoal produced in such environment would be higher than wildfire residues (Bird et al., 2015). In the studied CHAR soils, the presence of PyOM amongst occluded LF and OM in the HF shows that its stability is not exclusively explained by its chemical structure but further enhanced by a decreased accessibility for microorganisms (Brodowski et al., 2006; Lützow et al., 2006). Charcoal-mineral associations likely increase with PyOM ageing through increasing proportions of functional groups on the charcoal surfaces as well as the occurrence of biotic or abiotic binding agents (Brodowski et al., 2006; Kögel-Knabner et al., 2008; Kopittke et al., 2020). Finally, our results show increased amounts of non-PyOM in charcoal rich soils which suggests PyOM may influence the stability of non-PyOM in soils by serving as a hotspot for its sorption onto already existing organo-mineral clusters (Kopittke et al., 2020) or by creating microaggregates in which it becomes physically inaccessible to decomposers.

\section{Conclusion}

Our work combined for the first time thermal and elemental analyses on soil fractions extracted from a unique setting where PyOM from kiln sites was incorporated in conventionally cropped systems for over two centuries.

The $\mathrm{C}$ content of CHAR soils was significantly higher than that of adjacent REF soils thus confirming the potential of PyOM as a tool for $\mathrm{C}$ storage over centuries. Furthermore, our results show that such increases in $\mathrm{C}$ content were not solely attributed to increases in PyOM content, but also to additional non-PyOM accumulation in CHAR soils. The presence of PyOM in all soil fractions showed that after centuries of incorporation in strongly anthropogenized environments PyOM still stands as free LF yet also strongly associates with mineral phases. This association occurs through occlusion into aggregates and sorption of PyOM onto mineral surfaces. Compared to fresh PyOM, century-old PyOM isolated from charcoal rich soils showed higher $\mathrm{H}: \mathrm{C}$ and $\mathrm{O}: \mathrm{C}$ atomic ratios particularly in occluded LF vouching for a functionalization of the PyOM. As such its reactivity with other soil constituents increases as suggested by increased $\mathrm{Ca}^{2+}$ concentrations in CHAR soils. Furthermore, similar $\mathrm{C}: \mathrm{N}$ ratios in CHAR and REF fractions suggest increased amounts of $\mathrm{N}$-rich organic products in charcoal rich soils which probably serve as binding agents between PyOM and mineral phases. As a result of more binding sites, we observed increased amounts of water stable macroaggregate in CHAR soils. The related improved soil structure in charcoal rich soils is fundamental in maintaining fundamental ecosystems services such as diminished erosion and enhanced plant primary production.

Our results highlight that beyond its chemical composition, PyOM is further stabilized by organo-mineral associations and can not only serve as a $C$ sequestration tool but also as a mean to improve the soil quality of conventionally cropped agroecosystems in temperate Luvisols. 


\section{Acknowledgments}

We would like to thank colleagues from the water-soil-plant exchange lab and in particular F. de Tombeur for their help and guidance during the soil fractionation phase. We also thank Robin Giger from Agroscope in Zurich for his help and guidance using the DSC and the elemental analyzer. Access to the research site was granted by Alexandre Godfrind who's help and availability we acknowledge. We thank colleagues from the CHAR project for the fruitful scientific discussions and the support during field work. This research was funded as a Concerted Research Action (ARC) by the French Community of Belgium and written within the CHAR research project.

\section{References}

Amelung, W., Zech, W., 1999. Minimisation of organic matter disruption during particle-size fractionation of grassland epipedons. Geoderma 92, 73-85. https://doi.org/10.1016/S00167061(99)00023-3

Aufdenkampe, A.K., Hedges, J.I., Richey, J.E., Krusche, A. V., Llerena, C.A., 2001. Sorptive fractionation of dissolved organic nitrogen and amino acids onto fine sediments within the Amazon Basin. Limnol. Oceanogr. 46, 1921-1935. https://doi.org/10.4319/lo.2001.46.8.1921

Awad, Y.M., Blagodatskaya, E., Ok, Y.S., Kuzyakov, Y., 2013. Effects of polyacrylamide, biopolymer and biochar on the decomposition of $14 \mathrm{C}$-labelled maize residues and on their stabilization in soil aggregates. Eur. J. Soil Sci. 64, 488-499. https://doi.org/10.1111/ejss.12034

Barré, P., Plante, A.F., Cécillon, L., Lutfalla, S., Baudin, F., Bernard, S., Christensen, B.T., Eglin, T., Fernandez, J.M., Houot, S., Kätterer, T., Le Guillou, C., Macdonald, A., van Oort, F., Chenu, C., 2016. The energetic and chemical signatures of persistent soil organic matter. Biogeochemistry 130. https://doi.org/10.1007/s10533-016-0246-0

Baveye, P.C., 2020. Bypass and hyperbole in soil research: Worrisome practices critically reviewed through examples. Eur. J. Soil Sci. 1-20. https://doi.org/10.1111/ejss.12941

Baveye, P.C., 2014. The Characterization of Pyrolysed Biomass Added to Soils Needs to Encompass Its Physical And Mechanical Properties. Soil Sci. Soc. Am. J. 78, 2112-2113. https://doi.org/10.2136/sssaj2014.09.0354l

Bell, C., Carrillo, Y., Boot, C.M., Rocca, J.D., Pendall, E., Wallenstein, M.D., 2014. Rhizosphere stoichiometry: are $\mathrm{C}: \mathrm{N}: \mathrm{P}$ ratios of plants, soils, and enzymes conserved the plant species-level? New Phytol. 201, 505-517. https://doi.org/10.1111/nph.12531

Biederman, L.A., Harpole, S.W., 2013. Biochar and its effects on plant productivity and nutrient cycling: A meta-analysis. Glob. Chang. Biol. Bioenergy 5, 202-214. https://doi.org/10.1111/gcbb.12037

Bird, M.I., Wynn, J.G., Saiz, G., Wurster, C.M., McBeath, A., 2015. The Pyrogenic Carbon Cycle. Annu. Rev. Earth Planet. Sci. 43, 273-298. https://doi.org/10.1146/annurev-earth-060614-105038

Borchard, N., Ladd, B., Eschemann, S., Hegenberg, D., Möseler, B.M., Amelung, W., 2014. Black carbon and soil properties at historical charcoal production sites in Germany. Geoderma 232-234, 236- 
242. https://doi.org/10.1016/j.geoderma.2014.05.007

Brodowski, S., Amelung, W., Haumaier, L., Abetz, C., Zech, W., 2005. Morphological and chemical properties of black carbon in physical soil fractions as revealed by scanning electron microscopy and energy-dispersive X-ray spectroscopy. Geoderma 128, 116-129. https://doi.org/10.1016/j.geoderma.2004.12.019

Brodowski, S., John, B., Flessa, H., Amelung, W., 2006. Aggregate-occluded black carbon in soil. Eur. J. Soil Sci. 57, 539-546. https://doi.org/10.1111/j.1365-2389.2006.00807.x

Cheng, C.-H., Lehmann, J., Engelhard, M.H., 2008a. Natural oxidation of black carbon in soils: Changes in molecular form and surface charge along a climosequence. Geochim. Cosmochim. Acta 72, 15981610. https://doi.org/10.1016/j.gca.2008.01.010

Cheng, C.-H., Lehmann, J., Thies, J.E., Burton, S.D., 2008b. Stability of black carbon in soils across a climatic gradient. J. Geophys. Res. Biogeosciences 113, 1-10. https://doi.org/10.1029/2007JG000642

Cheng, C.H., Lehmann, J., 2009. Ageing of black carbon along a temperature gradient. Chemosphere 75, 1021-1027. https://doi.org/10.1016/j.chemosphere.2009.01.045

Cheng, C.H., Lehmann, J., Thies, J.E., Burton, S.D., Engelhard, M.H., 2006. Oxidation of black carbon by biotic and abiotic processes. Org. Geochem. 37, 1477-1488. https://doi.org/10.1016/j.orggeochem.2006.06.022

Chenu, C., Angers, D.A., Barré, P., Derrien, D., Arrouays, D., Balesdent, J., 2019. Increasing organic stocks in agricultural soils: Knowledge gaps and potential innovations. Soil Tillage Res. 188, 41-52. https://doi.org/10.1016/j.still.2018.04.011

Chenu, C., Plante, A.F., 2006. Clay-sized organo-mineral complexes in a cultivation chronosequence: revisiting the concept of the "primary organo-mineral complex." Eur. J. Soil Sci. 57, 596-607. https://doi.org/10.1111/j.1365-2389.2006.00834.x

Crane-Droesch, A., Abiven, S., Jeffery, S., Torn, M.S., 2013. Heterogeneous global crop yield response to biochar: a meta-regression analysis. Environ. Res. Lett. 8, 044049. https://doi.org/10.1088/17489326/8/4/044049

De la Rosa, J.M., Knicker, H., López-Capel, E., Manning, D.A.C., González-Perez, J.A., González-Vila, F.J., 2008. Direct Detection of Black Carbon in Soils by Py-GC/MS, Carbon-13 NMR Spectroscopy and Thermogravimetric Techniques. Soil Sci. Soc. Am. J. 72, 258-267. https://doi.org/10.2136/sssaj2007.0031

Dell'Abate, M.T., Benedetti, A., Sequi, P., 2000. Thermal methods of organic matter maturation monitoring during a composting process. J. Therm. Anal. Calorim. 61, 389-396. https://doi.org/https://doi.org/10.1023/A:1010157115211

Dungait, J.A.J., Hopkins, D.W., Gregory, A.S., Whitmore, A.P., 2012. Soil organic matter turnover is 
governed by accessibility not recalcitrance. Glob. Chang. Biol. 18, 1781-1796. https://doi.org/10.1111/j.1365-2486.2012.02665.x

Fang, Y., Singh, B., Singh, B.P., 2015. Effect of temperature on biochar priming effects and its stability in soils. Soil Biol. Biochem. 80, 136-145. https://doi.org/10.1016/j.soilbio.2014.10.006

Forbes, M.S., Raison, R.J., Skjemstad, J.O., 2006. Formation, transformation and transport of black carbon (charcoal) in terrestrial and aquatic ecosystems. Sci. Total Environ. 370, 190-206. https://doi.org/10.1016/j.scitotenv.2006.06.007

Glaser, B., Balashov, E., Haumaier, L., Guggenberger, G., Zech, W., 2000. Black carbon in density fractions of anthropogenic soils of the Brazilian Amazon region. Org. Geochem. 31, 669-678. https://doi.org/10.1016/S0146-6380(00)00044-9

Glaser, B., Birk, J.J., 2012. State of the scientific knowledge on properties and genesis of Anthropogenic Dark Earths in Central Amazonia (terra preta de Índio). Geochim. Cosmochim. Acta 82, 39-51. https://doi.org/10.1016/j.gca.2010.11.029

Grunwald, D., Kaiser, M., Junker, S., Marhan, S., Piepho, H.-P., Poll, C., Bamminger, C., Ludwig, B., 2017. Influence of elevated soil temperature and biochar application on organic matter associated with aggregate-size and density fractions in an arable soil. Agric. Ecosyst. Environ. 241, 79-87. https://doi.org/10.1016/j.agee.2017.02.029

Gulde, S., Chung, H., Amelung, W., Chang, C., Six, J., 2008. Soil Carbon Saturation Controls Labile and Stable Carbon Pool Dynamics. Soil Sci. Soc. Am. J. 72, 605-612. https://doi.org/10.2136/sssaj2007.0251

Hagemann, N., Joseph, S., Schmidt, H.-P., Kammann, C.I., Harter, J., Borch, T., Young, R.B., Varga, K., Taherymoosavi, S., Elliott, K.W., McKenna, A., Albu, M., Mayrhofer, C., Obst, M., Conte, P., DieguezAlonso, A., Orsetti, S., Subdiaga, E., Behrens, S., Kappler, A., 2017. Organic coating on biochar explains its nutrient retention and stimulation of soil fertility. Nat. Commun. 8, 1089. https://doi.org/10.1038/s41467-017-01123-0

Hamer, U., Marschner, B., Brodowski, S., Amelung, W., 2004. Interactive priming of black carbon and glucose mineralisation. Org. Geochem. 35, 823-830. https://doi.org/10.1016/j.orggeochem.2004.03.003

Hammes, K., Schmidt, M.W.I., Smernik, R.J., Currie, L.A., Ball, W.P., Nguyen, T.H., Louchouarn, P., Houel, S., Gustafsson, Ö., Elmquist, M., Cornelissen, G., Skjemstad, J.O., Masiello, C.A., Song, J., Peng, P., Mitra, S., Dunn, J.C., Hatcher, P.G., Hockaday, W.C., Smith, D.M., Hartkopf-Fröder, C., Böhmer, A., Lüer, B., Huebert, B.J., Amelung, W., Brodowski, S., Huang, L., Zhang, W., Gschwend, P.M., FloresCervantes, D.X., Largeau, C., Rouzaud, J.-N., Rumpel, C., Guggenberger, G., Kaiser, K., Rodionov, A., Gonzalez-Vila, F.J., Gonzalez-Perez, J.A., de la Rosa, J.M., Manning, D.A.C., López-Capél, E., Ding, L., 2007. Comparison of quantification methods to measure fire-derived (black/elemental) carbon in soils and sediments using reference materials from soil, water, sediment and the atmosphere. Global Biogeochem. Cycles 21, n/a-n/a. https://doi.org/10.1029/2006GB002914 
Hammes, K., Torn, M.S., Lapenas, A.G., Schmidt, M.W.I., 2008. Centennial black carbon turnover observed in a Russian steppe soil. Biogeosciences 5, 1339-1350. https://doi.org/10.5194/bg-51339-2008

Hardy, B., Cornelis, J.-T., Houben, D., Leifeld, J., Lambert, R., Dufey, J.E., 2017a. Evaluation of the longterm effect of biochar on properties of temperate agricultural soil at pre-industrial charcoal kiln sites in Wallonia, Belgium. Eur. J. Soil Sci. 68, 80-89. https://doi.org/10.1111/ejss.12395

Hardy, B., Dufey, J., 2015. Les aires de faulde en forêt wallonne : repérage, morphologie et distribution spatiale. Forêt Nat. 135, 20-30.

Hardy, B., Leifeld, J., Knicker, H., Dufey, J.E., Deforce, K., Cornélis, J.-T., 2017b. Long term change in chemical properties of preindustrial charcoal particles aged in forest and agricultural temperate soil. Org. Geochem. 107, 33-45. https://doi.org/10.1016/j.orggeochem.2017.02.008

Heidarian Dehkordi, R., Denis, A., Fouche, J., Burgeon, V., Cornelis, J.T., Tychon, B., Placencia Gomez, E., Meersmans, J., 2020. Remotely-sensed assessment of the impact of century-old biochar on chicory crop growth using high-resolution UAV-based imagery. Int. J. Appl. Earth Obs. Geoinf. 91, 102147. https://doi.org/10.1016/j.jag.2020.102147

Herath, H.M.S.K., Camps-Arbestain, M., Hedley, M., Van Hale, R., Kaal, J., 2014. Fate of biochar in chemically- and physically-defined soil organic carbon pools. Org. Geochem. 73, 35-46. https://doi.org/10.1016/j.orggeochem.2014.05.001

Hernandez-Soriano, M.C., Kerré, B., Goos, P., Hardy, B., Dufey, J., Smolders, E., 2016a. Long-term effect of biochar on the stabilization of recent carbon: soils with historical inputs of charcoal. GCB Bioenergy 8, 371-381. https://doi.org/10.1111/gcbb.12250

Hernandez-Soriano, M.C., Kerré, B., Kopittke, P.M., Horemans, B., Smolders, E., 2016b. Biochar affects carbon composition and stability in soil: a combined spectroscopy-microscopy study. Sci. Rep. 6, 25127. https://doi.org/10.1038/srep25127

Hirsch, F., Raab, T., Ouimet, W., Dethier, D., Schneider, A., Raab, A., 2017. Soils on historic charcoal hearths: Terminology and chemical properties. Soil Sci. Soc. Am. J. 81, 1427-1435. https://doi.org/10.2136/sssaj2017.02.0067

IUSS Working Group WRB. 2014. World Reference Base for Soil Resources 2014. International soil classification system for naming soils and creating legends for soil maps. World Soil Resources Reports No. 106. FAO, Rome

Jeffery, S., Verheijen, F.G.A., van der Velde, M., Bastos, A.C., 2011. A quantitative review of the effects of biochar application to soils on crop productivity using meta-analysis. Agric. Ecosyst. Environ. 144, 175-187. https://doi.org/10.1016/j.agee.2011.08.015

Kalinichev, A.G., Kirkpatrick, R.J., 2007. Molecular dynamics simulation of cationic complexation with natural organic matter. Eur. J. Soil Sci. 58, 909-917. https://doi.org/10.1111/j.13652389.2007.00929.x 
Kerré, B., Bravo, C.T., Leifeld, J., Cornelissen, G., Smolders, E., 2016. Historical soil amendment with charcoal increases sequestration of non-charcoal carbon: A comparison among methods of black carbon quantification. Eur. J. Soil Sci. 67, 324-331. https://doi.org/10.1111/ejss.12338

Kerré, B., Willaert, B., Smolders, E., 2017. Lower residue decomposition in historically charcoal-enriched soils is related to increased adsorption of organic matter. Soil Biol. Biochem. 104, 1-7. https://doi.org/10.1016/j.soilbio.2016.10.007

Kleber, M., Eusterhues, K., Keiluweit, M., Mikutta, C., Mikutta, R., Nico, P.S., 2015. Mineral-Organic Associations: Formation, Properties, and Relevance in Soil Environments, in: Advances in Agronomy. Elsevier Ltd, pp. 1-140. https://doi.org/10.1016/bs.agron.2014.10.005

Kleber, M., Sollins, P., Sutton, R., 2007. A conceptual model of organo-mineral interactions in soils: Selfassembly of organic molecular fragments into zonal structures on mineral surfaces. Biogeochemistry 85, 9-24. https://doi.org/10.1007/s10533-007-9103-5

Kögel-Knabner, I., Guggenberger, G., Kleber, M., Kandeler, E., Kalbitz, K., Scheu, S., Eusterhues, K., Leinweber, P., 2008. Organo-mineral associations in temperate soils: Integrating biology, mineralogy, and organic matter chemistry. J. Plant Nutr. Soil Sci. 171, 61-82. https://doi.org/10.1002/jpln.200700048

Kopittke, P.M., Dalal, R.C., Hoeschen, C., Li, C., Menzies, N.W., Mueller, C.W., 2020. Soil organic matter is stabilized by organo-mineral associations through two key processes: The role of the carbon to nitrogen ratio. Geoderma 357, 113974. https://doi.org/10.1016/j.geoderma.2019.113974

Kuzyakov, Y., Bogomolova, I., Glaser, B., 2014. Biochar stability in soil: Decomposition during eight years and transformation as assessed by compound-specific $14 \mathrm{C}$ analysis. Soil Biol. Biochem. 70, 229236. https://doi.org/10.1016/j.soilbio.2013.12.021

Lakanen, E., Erviö, R., 1971. A comparison of eight extractants for the determination of plant available micronutrients in soils. Acta Agral. Fenn. 123, 223-232.

Lal, R., 2004. Soil Carbon Sequestration Impacts on Global Climate Change and Food Security. Science (80-. ). 304, 1623.

Le Quéré, C., Raupach, M.R., Canadell, J.G., Marland, G., Bopp, L., Ciais, P., Conway, T.J., Doney, S.C., Feely, R.A., Foster, P., Friedlingstein, P., Gurney, K., Houghton, R.A., House, J.I., Huntingford, C., Levy, P.E., Lomas, M.R., Majkut, J., Metzl, N., Ometto, J.P., Peters, G.P., Prentice, I.C., Randerson, J.T., Running, S.W., Sarmiento, J.L., Schuster, U., Sitch, S., Takahashi, T., Viovy, N., van der Werf, G.R., Woodward, F.I., 2009. Trends in the sources and sinks of carbon dioxide. Nat. Geosci. 2, 831836. https://doi.org/10.1038/ngeo689

Lehmann, J., Gaunt, J., Rondon, M., 2006. Bio-char Sequestration in Terrestrial Ecosystems - A Review. Mitig. Adapt. Strateg. Glob. Chang. 11, 403-427. https://doi.org/10.1007/s11027-005-9006-5

Lehmann, J., Hansel, C.M., Kaiser, C., Kleber, M., Maher, K., Manzoni, S., Nunan, N., Reichstein, M., Schimel, J.P., Torn, M.S., Wieder, W.R., Kögel-Knabner, I., 2020. Persitence of soil organic carbon 
caused by functional complexity. Nat. Geosci. 13, 529-534. https://doi.org/10.1038/s41561-0200612-3

Lehmann, J., Kleber, M., 2015. The contentious nature of soil organic matter. Nature 528, 60-68. https://doi.org/10.1038/nature16069

Lehmann, J., Liang, B., Solomon, D., Lerotic, M., Luizão, F., Kinyangi, J., Schäfer, T., Wirick, S., Jacobsen, C., 2005. Near-edge X-ray absorption fine structure (NEXAFS) spectroscopy for mapping nano-scale distribution of organic carbon forms in soil: Application to black carbon particles. Global Biogeochem. Cycles 19, 1-12. https://doi.org/10.1029/2004GB002435

Lehmann, J., Rillig, M.C., Thies, J., Masiello, C.A., Hockaday, W.C., Crowley, D., 2011. Biochar effects on soil biota - A review. Soil Biol. Biochem. 43, 1812-1836. https://doi.org/10.1016/j.soilbio.2011.04.022

Lehndorff, E., Roth, P.J., Cao, Z.H., Amelung, W., 2014. Black carbon accrual during 2000 years of paddyrice and non-paddy cropping in the Yangtze River Delta, China. Glob. Chang. Biol. 20, 1968-1978. https://doi.org/10.1111/gcb.12468

Leifeld, J., 2008. Calorimetric characterization of grass during its decomposition. J. Therm. Anal. Calorim. 93, 651-655. https://doi.org/10.1007/s10973-007-8852-7

Leifeld, J., 2007. Thermal stability of black carbon characterised by oxidative differential scanning calorimetry. Org. Geochem. 38, 112-127. https://doi.org/10.1016/j.orggeochem.2006.08.004

Leinweber, P., Schulten, H.R., Horte, C., 1992. Differential thermal analysis, thermogravimetry and pyrolysis-field ionisation mass spectrometry of soil organic matter in particle-size fractions and bulk soil samples. Thermochim. Acta 194, 175-187. https://doi.org/10.1016/0040-6031(92)80016$P$

Liang, B., Lehmann, J., Sohi, S.P., Thies, J.E., O’Neill, B., Trujillo, L., Gaunt, J., Solomon, D., Grossman, J., Neves, E.G., Luizão, F.J., O’Neill, B., Trujillo, L., Gaunt, J., Solomon, D., Grossman, J., Neves, E.G., Luizão, F.J., 2010. Black carbon affects the cycling of non-black carbon in soil. Org. Geochem. 41, 206-213. https://doi.org/10.1016/j.orggeochem.2009.09.007

Lopez-Capel, E., Sohi, S.P., Gaunt, J.L., Manning, D.A.C., 2005. Use of Thermogravimetry-Differential Scanning Calorimetry to characterize modelable soil organic matter fractions. Soil Sci. Soc. Am. J. 69, 136-140.

Lorenz, K., Lal, R., 2014. Biochar application to soil for climate change mitigation by soil organic carbon sequestration. J. Plant Nutr. Soil Sci. 177, 651-670. https://doi.org/10.1002/jpln.201400058

Lutfalla, S., Abiven, S., Barré, P., Wiedemeier, D.B., Christensen, B.T., Houot, S., Kätterer, T., Macdonald, A.J., van Oort, F., Chenu, C., 2017. Pyrogenic Carbon Lacks Long-Term Persistence in Temperate Arable Soils. Front. Earth Sci. 5, 1-10. https://doi.org/10.3389/feart.2017.00096

Lützow, M. V., Kögel-Knabner, I., Ekschmitt, K., Matzner, E., Guggenberger, G., Marschner, B., Flessa, H., 
2006. Stabilization of organic matter in temperate soils: Mechanisms and their relevance under different soil conditions - A review. Eur. J. Soil Sci. 57, 426-445. https://doi.org/10.1111/j.13652389.2006.00809.x

Meier, I.C., Finzi, A.C., Phillips, R.P., 2017. Root exudates increase $\mathrm{N}$ availability by stimulating microbial turnover of fast-cycling N pools. Soil Biol. Biochem. 106, 119-128. https://doi.org/10.1016/j.soilbio.2016.12.004

Minasny, B., Malone, B.P., McBratney, A.B., Angers, D.A., Arrouays, D., Chambers, A., Chaplot, V., Chen, Z.-S., Cheng, K., Das, B.S., Field, D.J., Gimona, A., Hedley, C.B., Hong, S.Y., Mandal, B., Marchant, B.P., Martin, M., McConkey, B.G., Mulder, V.L., O’Rourke, S., Richer-de-Forges, A.C., Odeh, I., Padarian, J., Paustian, K., Pan, G., Poggio, L., Savin, I., Stolbovoy, V., Stockmann, U., Sulaeman, Y., Tsui, C.-C., Vågen, T.-G., van Wesemael, B., Winowiecki, L., 2017. Soil carbon 4 per mille. Geoderma 292, 59-86. https://doi.org/10.1016/j.geoderma.2017.01.002

Moni, C., Rumpel, C., Virto, I., Chabbi, A., Chenu, C., 2010. Relative importance of sorption versus aggregation for organic matter storage in subsoil horizons of two contrasting soils. Eur. J. Soil Sci. 61, 958-969. https://doi.org/10.1111/j.1365-2389.2010.01307.x

Nguyen, B.T., Lehmann, J., Kinyangi, J., Smernik, R., Riha, S.J., Engelhard, M.H., 2008. Long-term black carbon dynamics in cultivated soil. Biogeochemistry 89, 295-308. https://doi.org/10.1007/s10533008-9220-9

Pituello, C., Dal Ferro, N., Francioso, O., Simonetti, G., Berti, A., Piccoli, I., Pisi, A., Morari, F., 2018. Effects of biochar on the dynamics of aggregate stability in clay and sandy loam soils. Eur. J. Soil Sci. 69, 827-842. https://doi.org/10.1111/ejss.12676

Plante, A.F., Fernández, J.M., Haddix, M.L., Steinweg, J.M., Conant, R.T., 2011. Biological, chemical and thermal indices of soil organic matter stability in four grassland soils. Soil Biol. Biochem. 43, 10511058. https://doi.org/10.1016/j.soilbio.2011.01.024

Plante, A.F., Fernández, J.M., Leifeld, J., 2009. Application of thermal analysis techniques in soil science. Geoderma 153, 1-10. https://doi.org/10.1016/j.geoderma.2009.08.016

Poeplau, C., Don, A., Six, J., Kaiser, M., Benbi, D., Chenu, C., Cotrufo, M.F., Derrien, D., Gioacchini, P., Grand, S., Gregorich, E., Griepentrog, M., Gunina, A., Haddix, M., Kuzyakov, Y., Kühnel, A., Macdonald, L.M., Soong, J., Trigalet, S., Vermeire, M.-L., Rovira, P., van Wesemael, B., Wiesmeier, M., Yeasmin, S., Yevdokimov, I., Nieder, R., 2018. Isolating organic carbon fractions with varying turnover rates in temperate agricultural soils - A comprehensive method comparison. Soil Biol. Biochem. 125, 10-26. https://doi.org/10.1016/j.soilbio.2018.06.025

Poirier, V., Roumet, C., Munson, A.D., 2018. The root of the matter: Linking root traits and soil organic matter stabilization processes. Soil Biol. Biochem. 120, 246-259. https://doi.org/10.1016/j.soilbio.2018.02.016

Rasse, D.P., Rumpel, C., Dignac, M., 2005. Is soil carbon mostly root carbon? Mechanisms for a specific 
stabilisation. Plant Soil 269, 341-356. https://doi.org/10.1007/s11104-004-0907-y

984

985

986

987

988

989

990

991

992

993

994

995

996

997

998

999

1000

1001

1002

1003

1004

1005

1006

1007

1008

1009

1010

1011

1012

1013

1014

1015

1016

1017

Rillig, M.C., 2004. Arbuscular mycorrhizae, glomalin, and soil aggregation. Can. J. Soil Sci. 84, 355-363. https://doi.org/10.4141/S04-003

Rodionov, A., Amelung, W., Peinemann, N., Haumaier, L., Zhang, X., Kleber, M., Glaser, B., Urusevskaya, I., Zech, W., 2010. Black carbon in grassland ecosystems of the world. Global Biogeochem. Cycles 24, 1-15. https://doi.org/10.1029/2009GB003669

Rovira, P., Kurz-Besson, C., Coûteaux, M.M., Ramón Vallejo, V., 2008. Changes in litter properties during decomposition: A study by differential thermogravimetry and scanning calorimetry. Soil Biol. Biochem. 40, 172-185. https://doi.org/10.1016/j.soilbio.2007.07.021

Sanderman, J., Hengl, T., Fiske, G.J., 2017. Soil carbon debt of 12,000 years of human land use. Proc. Natl. Acad. Sci. 114, 9575-9580. https://doi.org/10.1073/pnas.1706103114

Schmidt, M.W.I., Noack, A.G., 2000. Black carbon in soils and sediments: Analysis, distribution, implications and current challenges. Global Biogeochem. Cycles 14, 777-793.

Schmidt, M.W.I., Torn, M.S., Abiven, S., Dittmar, T., Guggenberger, G., Janssens, I.A., Kleber, M., KögelKnabner, I., Lehmann, J., Manning, D.A.C., Nannipieri, P., Rasse, D.P., Weiner, S., Trumbore, S.E., 2011. Persistence of soil organic matter as an ecosystem property. Nature 478, 49-56. https://doi.org/10.1038/nature10386

Schneider, A., Hirsch, F., Raab, A., Raab, T., 2019. Temperature Regime of a Charcoal-Enriched Land Use Legacy Soil. Soil Sci. Soc. Am. J. 83, 565-574. https://doi.org/10.2136/sssaj2018.12.0483

Singh, B.P., Cowie, A.L., Smernik, R.J., 2012. Biochar Carbon Stability in a Clayey Soil As a Function of Feedstock and Pyrolysis Temperature. Environ. Sci. Technol. 46, 11770-11778. https://doi.org/10.1021/es302545b

Singh, N., Abiven, S., Torn, M.S., Schmidt, M.W.I., 2012. Fire-derived organic carbon in soil turns over on a centennial scale. Biogeosciences 9, 2847-2857. https://doi.org/10.5194/bg-9-2847-2012

Six, J., Elliott, E.., Paustian, K., 2000. Soil macroaggregate turnover and microaggregate formation: a mechanism for $C$ sequestration under no-tillage agriculture. Soil Biol. Biochem. 32, 2099-2103. https://doi.org/10.1016/S0038-0717(00)00179-6

Six, J., Elliott, E.., Paustian, K., Doran, J.W., 1998. Aggregation and Soil Organic Matter Accumulation in Cultivated and Native Grassland Soils. Soil Sci. Soc. Am. J. 62, 1367-1377. https://doi.org/10.2136/sssaj1998.03615995006200050032x

Sun, F., Lu, S., 2014. Biochars improve aggregate stability, water retention, and pore-space properties of clayey soil. J. Plant Nutr. Soil Sci. 177, 26-33. https://doi.org/10.1002/jpln.201200639

Virto, I.C., Moni, C., Swanston, C., Chenu, C., 2010. Turnover of intra- and extra-aggregate organic matter at the silt-size scale. Geoderma 156, 1-10.

https://doi.org/10.1016/j.geoderma.2009.12.028 
1018

1019

1020

1021

1022

1023

1024

1025

1026

1027

1028

1029

1030

1031

1032

1033

1034

1035

1036

1037

1038

1039

1040

Vogel, C., Mueller, C.W., Höschen, C., Buegger, F., Heister, K., Schulz, S., Schloter, M., Kögel-Knabner, I., 2014. Submicron structures provide preferential spots for carbon and nitrogen sequestration in soils. Nat. Commun. 5, 2947. https://doi.org/10.1038/ncomms3947

von Lützow, M., Kögel-Knabner, I., Ekschmitt, K., Flessa, H., Guggenberger, G., Matzner, E., Marschner, B., 2007. SOM fractionation methods: Relevance to functional pools and to stabilization mechanisms. Soil Biol. Biochem. 39, 2183-2207. https://doi.org/10.1016/j.soilbio.2007.03.007

von Lützow, M., Kögel-Knabner, I., Ekschmitt, K., Matzner, E., Guggenberger, G., Marschner, B., Flessa, $\mathrm{H}$., 2006. Stabilization of organic matter in temperate soils: Mechanisms and their relevance under different soil conditions - A review. Eur. J. Soil Sci. 57, 426-445. https://doi.org/10.1111/j.13652389.2006.00809.x

Wang, J., Xiong, Z., Kuzyakov, Y., 2016. Biochar stability in soil: meta-analysis of decomposition and priming effects. Glob. Chang. Biol. Bioenergy 8, 512-523. https://doi.org/10.1111/gcbb.12266

Wiedemeier, D.B., Abiven, S., Hockaday, W.C., Keiluweit, M., Kleber, M., Masiello, C.A., McBeath, A. V., Nico, P.S., Pyle, L.A., Schneider, M.P.W., Smernik, R.J., Wiesenberg, G.L.B., Schmidt, M.W.I., 2015. Aromaticity and degree of aromatic condensation of char. Org. Geochem. 78, 135-143. https://doi.org/10.1016/j.orggeochem.2014.10.002

WRB, I., 2014. World Reference Base for Soil Resources. World Soil Resources Report 103 . Rome: Food and Agriculture Organization of the United Nations (2006), pp. 132, US\$22.00 (paperback). ISBN 92-5-10511-4. World Ref. Base Soil Resour. 3, 264-264. https://doi.org/10.1017/S0014479706394902

Zimmerman, A.R., Gao, B., Ahn, M.-Y., 2011. Positive and negative carbon mineralization priming effects among a variety of biochar-amended soils. Soil Biol. Biochem. 43, 1169-1179.

https://doi.org/10.1016/j.soilbio.2011.02.005 